MARCIA LAUDELINA ARRUDA TEMPERINI

\title{
ALGUNS ASPECTOS DA ESPECTROSCOPIA RAMAN RESSONANTE
}


Agradeco

Ao Prof. O.Sala pela orientacão;

ao Prof. H.J. Bernstein pelas sugestões e discussões;

ao Prof. K. Kawai pelos ensinamentos iniciais;

ao Prof. R. Forneris por sugestões e empréstimo de um

detetor termoelëtrico;

ao Prof. S.Isotani por discussões na parte teórica;

ao Prof. O.A.Serra pelas sugestões na obtengão dos

espectros eletrônicos;

aos colegas Yoshio, Yoshiyuki, Paulo e Alvaro pelas

discussões;

ao A.G.Ayrosa e S. Sato pela construgão de equipamentos;

ao Instituto de Geociência pelo uso do difratômetro de raio-x;

à Fundacão de Amparo à Pesquisa do Estado de São Paulo pelas bolsas concedidas. 
No estudo por espectroscopia vibracional, Raman e infravermelho, dos compostos $\mathrm{Cu}_{3} \mathrm{PS}_{4}$ e $\mathrm{Ag}_{3} \mathrm{PS}_{4}$ foi observado nos espectros Raman aumento na intensidade relativa de algumas bandas, para certas radiações excitantes, eviden ciando a presença de efeito Raman ressonante.

Alēm da discussão sobre a atribuição das frequên cias vibracionais apresentamos os perfís de excitação pa ra os modos internos do $\mathrm{Cu}_{3} \mathrm{PS}_{4}$ e $\mathrm{Ag}_{3} \mathrm{PS}_{4}$. Para o ion $\mathrm{MoS}_{4}{ }^{2-}$ apresentamos os perfís para o modo de estiramento simetri co e sua primeira harmônica, tanto do lado stokes como do lado anti-Stokes.

No estudo dos compostos no estado sólido introduzimos um método de correção para intensidade atravēs dos espectros Raman. Introduzimos, também, uma maneira diferente de representar o perfil de excitação, onde se evi dencia melhor o efeito ressonante. Os perfís mostram para - $\mathrm{Cu}_{3} \mathrm{PS}_{4}$ efeito Raman ressonante rigoroso, enquanto que o $\mathrm{Ag}_{3} \mathrm{PS}_{4}$ apresenta somente efeito Raman pré-ressonante, na região observada.

Observamos um deslocamento sistemático do perfíl de excitação para frequências mais altas com o aumento da frequência vibracional. Interpretamos esse deslocamento co mo resultante da influência da frequência espalhada na in tensidade das bandas Raman. 
Os perfis de excitação obtidos são discutidos em termos da teoria de Peticolas e col. para o efeito Raman ressonante. Com base nesta teoria apresentamos um método de obter a frequência de absorção efetiva através da re lação de intensidades anti-Stokes/Stokes, que é aplicado no caso do $\operatorname{Mos}_{4}{ }^{2-}$.

As medidas da relação de intensidades anti-Stokes /Stokes confirmaram a dependência da intensidade, no efei to Raman ressonante, com a frequência da radiação espalhą da e não somente com a frequência da radiação incidente.

\section{ABSTRACT}

In the course of the vibrational spectroscopic study (Raman and infrared) of the compounds $\mathrm{Cu}_{3} \mathrm{PS}_{4}$ and $\mathrm{Ag}_{3} \mathrm{PS}_{4}$, it was observed in the Raman spectra an increase in the relative intensities of some bands, on using cer tain exciting lines, revealing Raman resonance effect.

Aside from the discussion on the vibrational fre quency assignment, we present the excitation profiles for the internal modes of $\mathrm{Cu}_{3} \mathrm{PS}_{4}$ and $\mathrm{Ag}_{3} \mathrm{PS}_{4}$. In the case of the $\operatorname{Mos}_{4}^{2-}$ ion, the profiles for the symmetric stretching and its first overtone is shown, both for the stokes as for the anti-stokes region.

In the case of the compounds investigated in the solid state, we introduced a method for the absorption 
correction on the intensity, trough the Raman spectra. We also introduced a different way for representing the excitation profile, where the resonance effect becomes more evident. The profiles show a rigorous Raman reso nance effect for $\mathrm{Cu}_{3} \mathrm{PS}_{4}$, while $\mathrm{Ag}_{3} \mathrm{PS}_{4}$ only reveal a preresonance effect, in the observed region.

We observed that the excitation profile shifts systematically to higher frequencies with increasing vibrational frequency. This was assigned as an influence of the scattered frequency on the intensity of the Raman bands.

The excitation profiles are discussed on basis of the Raman ressonance effect theory develloped by Peticolas et al. Making use of this theory we present a method for obtaining the effective absorption frequency trough the anti-stokes/stokes intensities relationship, and this method is applied for the $\operatorname{Mos}_{4}{ }^{2-}$ ion.

The measurements of the anti-Stokes/Stokes re lationship in the resonance region have confirmed a dependence of the intensity not only on the incident radiation frequency, but also on the scattered frequen cy. 
INDICE

Capitulo 121

1.1. Introdução 1

1.2. Principios bāsicos do efeito Raman ressonante 2

1.2.1. Tratamento de Albrecht 5

1.2.2. Tratamento de Peticolas 8

Capitulo2 12

2.1. Introdução 12

2.2. Resposta espectral do espectrómetro Raman 13

2.3. Largura espectral da fenda 16

$\begin{array}{ll}2.4 \text { Padrão interno } & 18\end{array}$

$\begin{array}{lll}2.5 & \text { Medida de intensidade } & 18\end{array}$

$\begin{array}{ll}\text { Capītulo } 3 & 20\end{array}$

$\begin{array}{ll}3.1 \text {. Introdução } & 20\end{array}$

3.2. Parte experimental 20

3.3. Atribuição das frequēncias 25

3.4. Variação da intensidade das bandas Raman com 35 a temperatura

3.5. Cālculo da anarmonicidade 38

3.6. Efeito Raman ressonante 40

3.6.1. Perfîl de excitação 48 
Capitulo $4 \quad 59$

4.1. Introdução 59

4.2. Atribuição das frequēncias 59

4.3. Efeito Raman ressonante 60

Capitulo $5 \quad 68$

5.1. Introdução 68

5.2. Parte experimental 70

5.3. Resultados e discussões 71 


\section{CAPITULO 1}

Introdução. Fundamentos da teoria do efeito Raman ressonante.

1. Introdução

Já nas primeiras teorias sobre o efeito Raman, obser va-se no denominador da expressão para a intensidade um ter mo dado pela diferença entre a frequência da banda de absorção eletrōnica e a frequēncia da radiação excitante, de modo que quando estas frequēncias se tornam prōximas deve haver um aumento considerāvel na intensidade.

Antes da utilização dos lasers na espectroscopia Ra man, os espectros eram geralmente obtidos por excitação com uma única radiação, o que tornava difícil que esta ressonāncia fosse notada, mesmo quando ela ocorresse. Assim, este au mento de intensidade causado pelo denominador de ressonáncia somente despertou interesse apōs a introdução de lasers na es pectroscopia Raman, com a possibilidade de utilização de uma gama apreciāvel de radiações.

Nesta tese fazemos alguns estudos sobre o efeito Ra man ressonante do $\mathrm{Cu}_{3} \mathrm{PS}_{4}, \mathrm{Ag}_{3} \mathrm{PS}_{4}$ e $\mathrm{MoS}_{4}{ }^{2-}$. As observações que fizemos nos espectros Raman ressonante do $\mathrm{Cu}_{3} \mathrm{PS}_{4}$, no es tado sōilido, sobre a dependēncia do aumento de intensidade não somente com a radiação excitante mas tambēm com a frequēr cia Raman espalhada, são fundamentais para a compreensão do fenōmeno. Embora esta dependēncia esteja contida implicitamen 
te nas teorias, e mesmo explicitamente em alguns trabalhos, parece que ela tem passada desapercebida nos trabalhos expe rimentais. 0 ion $\operatorname{MoS}_{4}{ }^{2-}$ foi investigado para melhor compro vação dos resultados obtidos com $0 \mathrm{Cu}_{3} \mathrm{PS}_{4}$, pois as correções rias medidas de intensidade de uma amostra em pó estão sujei tas a um erro relativamente grande.

Para $0 \mathrm{Cu}_{3} \mathrm{PS}_{4}$ e $\mathrm{Ag}_{3} \mathrm{PS}_{4}$ a lém do Raman foram obtidos os espectros de absorção no infravermelho e discutiremos a atribuição das frequências.

Embora este trabalho seja experimental, julgamos con veniente dar a seguir uma introdução teōrica sobre o Efeito Raman ressonante, desde que a contribuição mais importante da tese è neste campo.

1.2. Principios băsicos do efeito Raman ressonante

o espalhamento de luz por uma molécula pode ser en tendido atravēs do diagrama de nīveis de energia esquemati zado abaixo. No primeiro caso o fóton incidente hvo intera ge com a molécula levando-a a um estado virtual e,quedecai

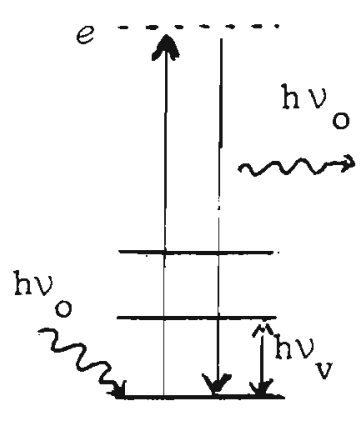

Rayleigh

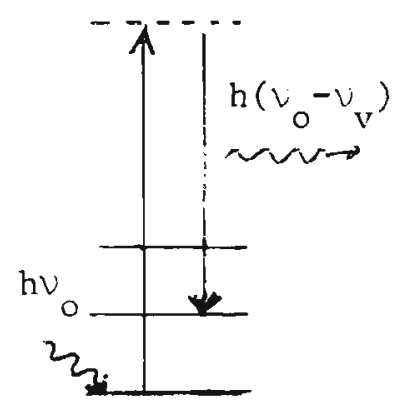

Stokes

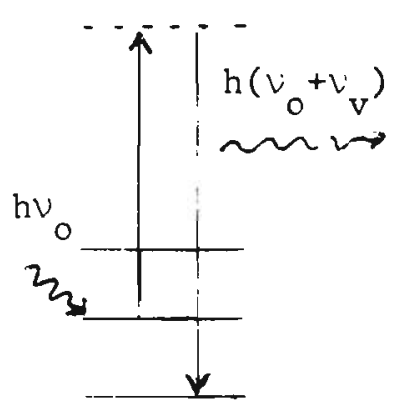

anti-stokes 
para o mesmo estado inicial dando o espalhamento Rayleigh, com frequéncia igual a do fóton incidente. No segundo caso, após a interação do fóton incidente com a molécula ela decai do estado virtual e para um estado vibracionalmente excita do e o föton espalhado terá frequência $v_{0}-v_{v}$, portanto menor do que a do incidente, dando o espalhamento Stokes. No ūiti mo caso o fóton hu encontra a molécula num estado vibracio nalmente excitado e apōs a interação hā decaimento para o es tado vibracional fundamental, sendo a frequēncia do fóton es palhado, $\nu_{0}+v_{v}$, maior do que a do incidente, dando origem à radiação anti-Stokes.

Este efeito foi previsto teoricamente por Smekal, em 1923, e confirmado experimentalmente por Raman e simultanea mente por Landsberg e Mandelstam, em 1928. Placzek, em 1934, apresentou uma teoria quantum-mecānica da polarizabilidade, que considera a perturbação causada pelo campo elétrico da radiação incidente nas funções de onda da molécula espalha dora. Obteve uma expressão para os elementos da matriz do nlomento de dipolo induzido $P_{m n}=\langle n ! P ! m\rangle$, onde $|m\rangle$ e $\langle n|$ são as funções de onda independentes do tempo, respectivamente, do estado inicial e final. Estes elementos de matriz estão relacionados com o campo elétrico da radiação incidente atra vēs do tensor de polarizabilidade: $F_{m n}=\left\langle n^{\prime} \alpha^{\prime} m\right\rangle \cdot E=\alpha_{m n} \cdot E$.

Sendo $\rho$ e $\sigma=x, y, z$, a componente $\rho, \sigma e ́ s i m a$ do ten sor de polarizabilidade édada pela equação de kramers e Heisenberg: 


$$
\left(\alpha_{\rho \sigma}\right)_{\mathrm{mn}}=\frac{1}{\mathrm{~h}} \sum_{e}\left[\frac{\left\langle\mathrm{n} \mathrm{R}_{\sigma} e\right\rangle\left\langle e\left|\mathrm{R}_{\rho}\right| \mathrm{m}\right\rangle}{v_{e \mathrm{~m}}-v_{0}}+\frac{\left\langle\mathrm{m}\left|\mathrm{R}_{\sigma}\right| e\right\rangle\left\langle e\left|\mathrm{R}_{\rho}\right| \mathrm{n}\right\rangle}{v_{e \mathrm{n}}+v_{0}}\right] \text {, }
$$

onde $R_{\sigma}$ e $R_{\rho}$ são os operadores de momento de dipolo eletrō nico $\left(R_{\sigma}=-\sum_{k} e\left(r_{k}\right)_{\sigma}\right.$, sendo $\left(r_{k}\right)_{\sigma}$ a componente $\sigma$ do vetor de posição do késimo elétron), $\nu_{e m} e \nu_{e n}$ são as frequēnci as correspondentes a diferença entre a energia dos estados intermediārios (e) e do estado inicial e final, respectiva mente.

A intensidade da luz espalhada seria:

$$
I_{m n} \propto\left(\nu_{0} \pm \nu_{m n}\right)^{4} \sum_{\rho \sigma}\left|\left(\alpha_{\rho \sigma}\right)_{m n}\right|^{2}
$$

Placzek expandiu a polarizabilidade numa sērie de Taylor das coordenadas nucleares do estado fundamental, trun cando a sērie no termo linear. Nesta aproximação a soma so bre os estados intermediārios na expressão (I) é formalmen te fechada, desaparecendo na nova expressão a dependéncia explicita destes estados, ficando somente as funções de on da do estado eletrōnico fundamental:

$$
\left(\alpha_{\rho \sigma}\right)_{m n}=\left\langle n\left|\alpha_{\rho \sigma}\right| m\right\rangle+\frac{\partial \alpha_{\rho \sigma}}{\partial Q_{i}}\left\langle n \cdot Q_{i}^{\prime} m\right\rangle
$$

Devido a ortogonalidade das funções de onda o pri meiro termo é nulo a menos que $m=n$ e representa o espalha mento Rayleigh. Admitindo funções de onda harmōnicas o se gundo termo sō é diferente de zero quando $n=m \pm 1$ e correspon 
de ao espalhamento Raman.

Com a descoberta do efeito Raman ressonante o papel dos estados excitados intermediārios na equação (I) tornouse importante, fazendo com que vārios teōricos voltassem a essa expressão e atravēs de diferentes aproximações chegas sem a uma expressão de intensidade da luz espalhada no efe to Raman ressonante. Iremos comentar agora alguns destes tra tamentos.

1.2.1. Tratamento de Albrecht

Albrecht ${ }^{1-3}$ considerou que as intensidades induzidas por acoplamento vibrōnico em transições eletrōnicas permiti das são responsāveis pelas intensidades Raman. Em particu lar, no efeito Raman ressonante seria justamente esse carac ter induzido vibracionalmente numa transição eletrōnica per mitida, cuja banda esta prōxima da frequência de excitação, que determina o aumento de intensidade de certas bandas Ra $\operatorname{man}$.

Albrecht deduziu uma equação que possibilita obter diretamente as regras de seleção, intensidade e outras pro priedades, especialmente o papel que os estados eletrōnicos excitados desempenham na intensidade Raman.

A teoria de Albrecht tem como ponto de partida a $\underline{e}$ quação de dispersão de Kramers-Heisemberg (equação (I)). Ad mite que as funções de onda eletrōnicas podem ser separadas das funções de onda vibracionais, isto é: 


$$
\begin{aligned}
& |m\rangle=|g i\rangle=|g\rangle|i\rangle \\
& |n\rangle=|g j\rangle=|g\rangle|j\rangle \\
& |e\rangle=|e v\rangle=|e\rangle|v\rangle
\end{aligned}
$$

onde $|g\rangle$ e $\mid$ e $>$ são as funções de onda dos estados eletrōni $\cos$ fundamental e excitado, $|i\rangle$ e $|j\rangle$ são as funções de onda vibracionais dos estados inicial e final, respectivamente, do estado eletrōnico fundamental e $|v\rangle \bar{e}$ a função de onda ví bracional do estado eletrônico excitado.

0 acoplamento entre os estados eletrónicos, via vi bracional, foi introduzido através da expansão de HerzbergTeller da função de onda eletrónica nas coordenadas normais, onde os coeficientes dos termos lineares são determinados pe 10 método de perturbação em primeira ordem:

$$
|e\rangle=\left|e^{o}\right\rangle+\sum_{a} \sum_{s \neq e} \frac{h_{e s}{ }^{a}}{E_{e}{ }^{o}-E_{s}{ }^{o}} Q_{a}\left|s^{0}\right\rangle
$$

onde $\left|e^{0}\right\rangle$ e $\left|s^{0}\right\rangle$ são estados eletrónicos excitados na confi guração de equilibrio do estado fundamental e hes a è a ener gia de perturbação por unidade de deslocamento do aésimo mo do normal $\left(Q_{a}\right)$ devida a mistura dos estados eletrónicos ex citados via perturbação vibracional, sendo dada por:

$$
h_{e s}{ }^{a}=\left\langle s^{0}\left|\left(\frac{\partial H}{\partial Q_{a}}\right)^{0}\right| e^{0}\right\rangle \text {. }
$$

Quando a frequência do fóton excitante é proxima à frequēncia de absorção eletrōnica, o denominador do primei ro termo da equação (I) torna-se pequeno, enquanto que 0 denominador do segundo termo é proximo a $2 v_{e n}$. Portanto, 0 
segundo termo da equação (I) pode ser desprezado, na condi ção de Raman ressonante. Para evitar que o valor da polari zabilidade, e em consequéncia o da intensidade, seja o quan do o denominador se anula e para tornar o valor compativel com o observado, deve-se introduzir um termo de amortecimen to $\Gamma_{e}$ no denominador. Com esta consideração e substituindo as funções de onda na equação (I) pelas expressões dadas em (II) a polarizabilidade pode ser escrita, na condição de Rá man ressonante:

$$
\left(\alpha_{\rho \sigma}\right)_{g i, g j}=\frac{1}{h} \sum_{e v}\left[\frac{\left\langle j g\left|R_{\sigma}\right| e v\right\rangle\left\langle v_{e}\left|R_{\rho}\right| g i\right\rangle}{v_{e v, g i}-v_{o}+i \Gamma_{e}}\right] .
$$

Levando em conta que para o estado eletrōnico funda mental $E_{g}-E_{S}{ }^{\circ}>>E_{e}{ }^{0}-E_{S}{ }^{0}$, pode-se considerar $|g\rangle=\left|g^{\circ}\right\rangle$.

Albrecht deduziu das equações (III) e (IV) uma ex pressão reduzida ao tipo $\left(\alpha_{\rho \sigma}\right)_{g i, g j}=A^{\prime \prime}{ }^{\prime}+B^{\prime \prime \prime}$, onde

$$
\begin{aligned}
& \begin{array}{l}
A^{\prime \prime \prime}=\frac{1}{h} \sum_{v}\left[\frac{\left(R_{\sigma}\right) g e}{{ }^{o}(R}\right) \\
v_{e v}, \\
B^{\prime \prime \prime}=\frac{-1}{h^{2}} \underset{\substack{\text { v s a } \\
\text { S }}}{\sum h_{e s}{ }^{a} x}
\end{array} \\
& \times\left[\frac{\left(R_{\sigma}\right)_{g e}{ }^{0}\left(R_{\rho}\right)_{g S}{ }^{0}\langle g j| e v>\left\langle e v\left|Q_{a}\right| g j\right\rangle+\left(R_{\rho}\right)_{g e}{ }^{0}\left(R_{\sigma}\right)_{g s}{ }^{0}\langle g i \mid e v\rangle\left\langle e v\left|Q_{a}\right| g j\right\rangle}{\left(\nu_{e v, g i}-\nu_{o}+i \Gamma_{e}\right)\left(\nu_{s}-\nu_{e}\right)}\right]
\end{aligned}
$$


o termo $A^{\prime \prime \prime}$ è dominante quando os estados eletrōn cos fundamental (g) e excitado (e) estão longe de outros es tados excitados. Este termo é o responsāvel pelo Raman res sonante das vibrações totalmente simētricas.

O termo $B^{\prime \prime}$, onde aparecem os termos de acoplamento vibrónico (hes ${ }^{a}$ ) entre dois estados eletrónicos excitados,e e s, é responsāvel pelo aumento de intensidade das frequēncias vibracionais que causam este acoplamento, e corresponde a parte não adiabātica do efeito Raman ressonante.

\subsubsection{Tratamento de Peticolas}

Peticolas ${ }^{4,5}$ desenvolveu uma teoria considerando o efeito Raman como um processo envolvendo um fóton incidente de energia hu, criação ou aniquilação de $n$ fonons de ener gia $h \Omega$ e um fóton emergente de energia $h\left(\nu_{0} \pm n \Omega\right)$, o sinal+ valendo para o espalhamento anti-Stokes e o - para o Szokes.

0 nümero de fonos, $n$, representa o estado vibracio nal excitado correspondente a nésima transição vibracional. Abaixo estão representados exemplos do diagrama usado para descrever o fenōmeno.

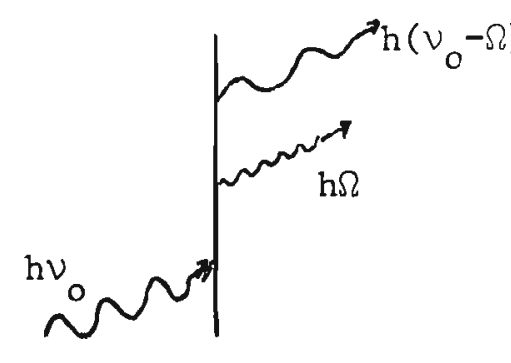

A

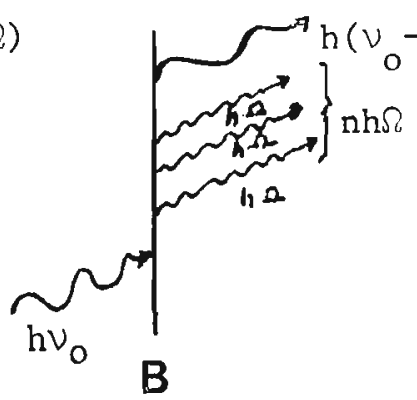

B

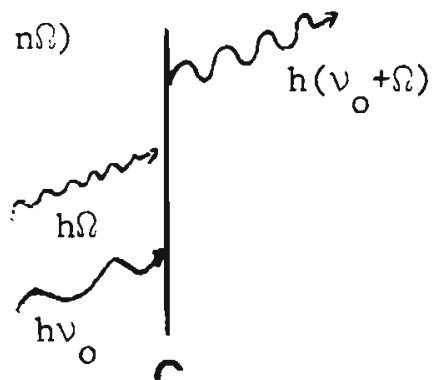

C 


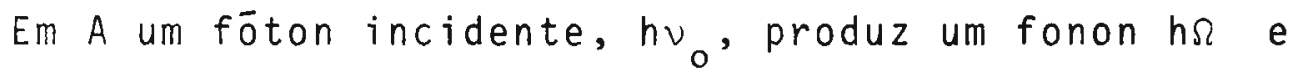
espalhamento Stokes $h\left(\nu_{0}-\Omega\right)$; em B ocorre o mesmo processo, mas com criação de $n$ fonons; em c ocorre o espalhamento antiStokes, com a aniquilação de um fonon.

Como resultado, Peticolas e col. obtiveram o elemen to do tensor de polarizabilidade na forma:

$$
\left(\alpha_{\rho \sigma}\right)_{g i, g j}=\frac{\left.\left(R_{\sigma}\right)_{g e}<e|\partial H / \partial Q| e\right\rangle^{n}\left(R_{\rho}\right)_{e g}}{\prod_{m=0}^{n}\left(E_{e} e^{\left.-E_{g}-\hbar \nu_{o} \pm m \hbar \Omega+i \Gamma_{e}\right)}\right.}
$$

onde, $E_{\epsilon}$ e $E_{g}$ são, respectivamente, a energia do estado ele trōnico excitado e fundamental, $\Omega \bar{e}$ a frequência do quantum vibracional e $n$ é a ordem da transição vibracional.o sinal + no denominador é valido para o espalhamento stokes e o si nal - para o espalhamento anti-stokes.

Considerando a equação acima, o primeiro fator no de nominador corresponde a $m=0$ e o elemento de matriz ( $\left.R_{p}\right)_{e g}$ vem do vērtice inferior do diagrama da pāgina anterior, que $\bar{e}$ a interação do föton incidente com o nível eletrōnico res sonante. Cada vértice do fonon corresponde ao fator:

$$
<e|\partial H / \partial Q| e>/\left(E_{e}-E_{g}-\hbar \nu_{o}+m \hbar \Omega+i \Gamma_{e}\right), \text { com } m=1,2, \ldots n \text {. }
$$

o vértice superior corresponde ao foton Raman emitido e dá origem ao elemento de matriz $\left(R_{\sigma}\right)_{g e}$.

A expressão para a intensidade $I_{n}$ de uma transição de ordem vibracional $n$ pode ser escrita: 


$$
I_{n}=K\left(\nu_{0} \pm n \Omega\right)^{4} B^{n} \frac{\left[\left(R_{\sigma}\right)_{g e}<e|\partial H / \partial Q| e>^{n}\left(R_{\rho}\right)_{e g}\right]^{2}}{\prod_{m=0}^{n}\left[\left(E_{e}-E_{g}-\hbar \nu_{0} \pm m \hbar \Omega\right)^{2}+\Gamma_{e}^{2}\right]}
$$

onde $B$ é o fator de Boltzmann ( $B=1$ para bandas Stokes e $B=\exp (-h \Omega / k T)$ para bandas anti-Stokes $)$ e $K \bar{e}$ uma constan te independente do nümero quāntico vibracional $\mathrm{n}$.

0 aumento de intensidade nas bandas de ordem vibra cional alta fica justificada pela expressão acima, pois na expressão da intensidade de uma harmōnica de ordem $n$ jāapa rece no denominador o termo $\left(E_{e}-E_{g}-\hbar \nu_{0} \pm \hbar \Omega\right)^{2}+\Gamma_{e}^{2} d a$ fundamen tal e pode-se dizer que as harmónicas entram en ressonāncia ao mesmo tempo que a fundamental. E interessante observar, pelo denominador de ressonância, que a intensidade de uma determinada harmônica pode sofrer maior aumento de intensi dade do que as outras, desde que ela satisfaça melhor a con dição de ressonāncia.

A expressão de Peticolas é mais poderosa do que a de Albrecht, pois permite calcular as intensidades das har mônicas e das bandas anti-stokes. Como no presente traba Tho estudamos a variação de intensidade das bandas funda mentais e harmōnicas, Stokes e anti-stokes, a comparação dos resultados experimentais de medidas de intensidade se rá feita com os valores teóricos obtidos da teoria de Peti colas. 


\section{REFERENCIAS}

1 Albrecht,A.C.: J.Chem.Phys.34, 1476 (1961).

? Tang,J. e Albrecht,A.C.: Raman Spectroscopy (Szymanski,H. A. ed.).Vol2-Cap.2. Plenum Press, N.Y. (1970).

3 Albrecht,A.C. e Hutley,M.C.: J.Chem.Phys.55, 4438 (1971).

4 Peticolas,W.L., Nafie,L., Stein,P. e Fanconi,B.: J.Chem. Phys.52, 1576 (1970).

5 Nafie,L.A., Stein,P. e Peticolas,W.L.: Chem.Phys. Letters 12, 131 (1971). 


\section{CAPITULO 2}

Parte experimental. Métodos de medida e de correção das in tensidades das bandas Raman.

\subsection{Introdução}

A maior parte do trabalho desta tese envolve medidas de intensidade das bandas Raman. Vārios fatores influenciam estas intensidades. Alguns destes fatores são essencialmente experimentais (como a geometria do espalhamento, condi ções da amostra, etc.) e instrumentais (como a eficiência do espectrômetro, resposta do detetor, etc.), enquanto que ou tros são característicos da amostra em estudo. Os fatores ex perimentais são em parte corrigidos quando se usa um padrão interno e em parte podem ser negligenciados quando se consi dera somente valores relativos de intensidade.

Neste capitulo descreveremos em mais detalhes as cor reções na intensidade que devem ser efetuadas devidas aos fatores instrumentais.

o espectrōmetro Raman utilizado foi um Jarrell-Ash mode10 25-300, duplo monocromador Czerny-Turner, constitui do por duas redes de difração idēnticas montadas num mesmo eixo, o que assegura àngulos identicos de rotação. As re des de difração possuem 1180 sulcos/mm e brilho ("blaze") em $500 \mathrm{~nm}$. A distância focal do instrumento é de $1,0 \mathrm{~m}$ e a resolução $0,25 \mathrm{~cm}^{-1} \mathrm{em} 630 \mathrm{~nm}$. 
O detetor utilizado é uma fotomultiplicadora ITTFW 130 , resfriada a $-22^{\circ} \mathrm{C}$, e o sinal amplificado por um am plificador $D C$.

2.2. Resposta espectral do espectrōmetro Raman

A eficiência de uma rede de difração depende do es tado de polarização da luz incidente e do ângulo de brilho da mesma e sua dependência com o comprimento de onda pode ser bastante complicada, como se observa na figura abaixo. Além desta variação da eficiência da rede de difração temos de considerar a sensibilidade espectral da fotomultiplicado ra (V.figura abaixo) e estes dois fatores irão determinar, essencialmente, a resposta espectral do instrumento.

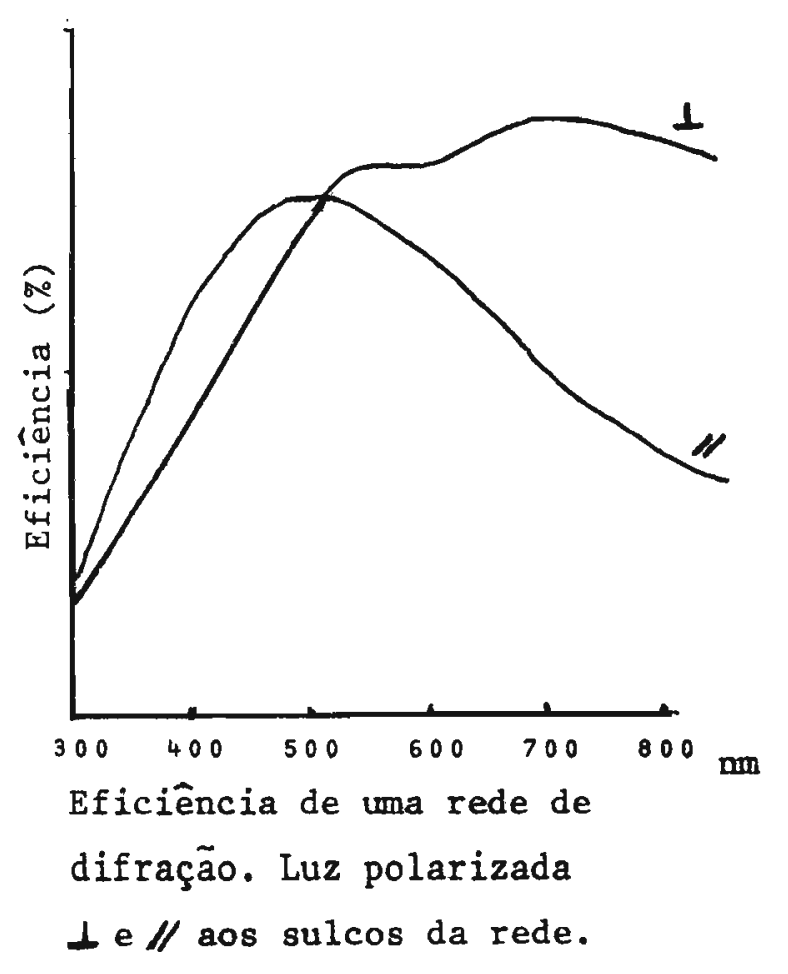


Para medidas de intensidade é necessārio, portanto, conhecer a resposta espectral do instrumento, para efetuar a devida correção. Geralmente, emprega-se para obter esta resposta uma lâmpada padrão e compara-se o espectro obtido da mesma com o da curva de emissão fornecida.

Como não possuimos uma lâmpada padrão,utilizamos $\underline{u}$ ma lâmpada de tungstênio de filamento retilineo (lâmpada de projetor), fixamos o valor da corrente elétrica e medimos as intensidades relativas num monocromador Hilger D187, com prisma de quartzo, usando como detetor uma pilha termoelétrica, cuja resposta é diretamente proporcional a energia in cidente, independendo do comprimento de onda.

os valores obtidos foram corrigidos para a variação da dispersão do monocromador ao longo do espectro, o que cor responde a manter a largura espectral da fenda constante (a largura mecânica foi mantida constante).

A temperatura do filamento da lämpada $(2500 \mathrm{~K})$ foi medida com um pirômetro ótico e supondo obedecida a equação de Planck para a radiação de um corpo negro comparamos a cur va experimental com a teórica. O resultado é mostrado na Fi gura 2.1 , observando-se boa concordância na região do visível, que é a que nos interessa. Acima de $1200 \mathrm{~nm}$ hä uma di vergēncia entre as duas curvas, que pode ser devida à falha na resposta do monocromador ou na aproximação da emissão da lämpada com a de um corpo negro. 


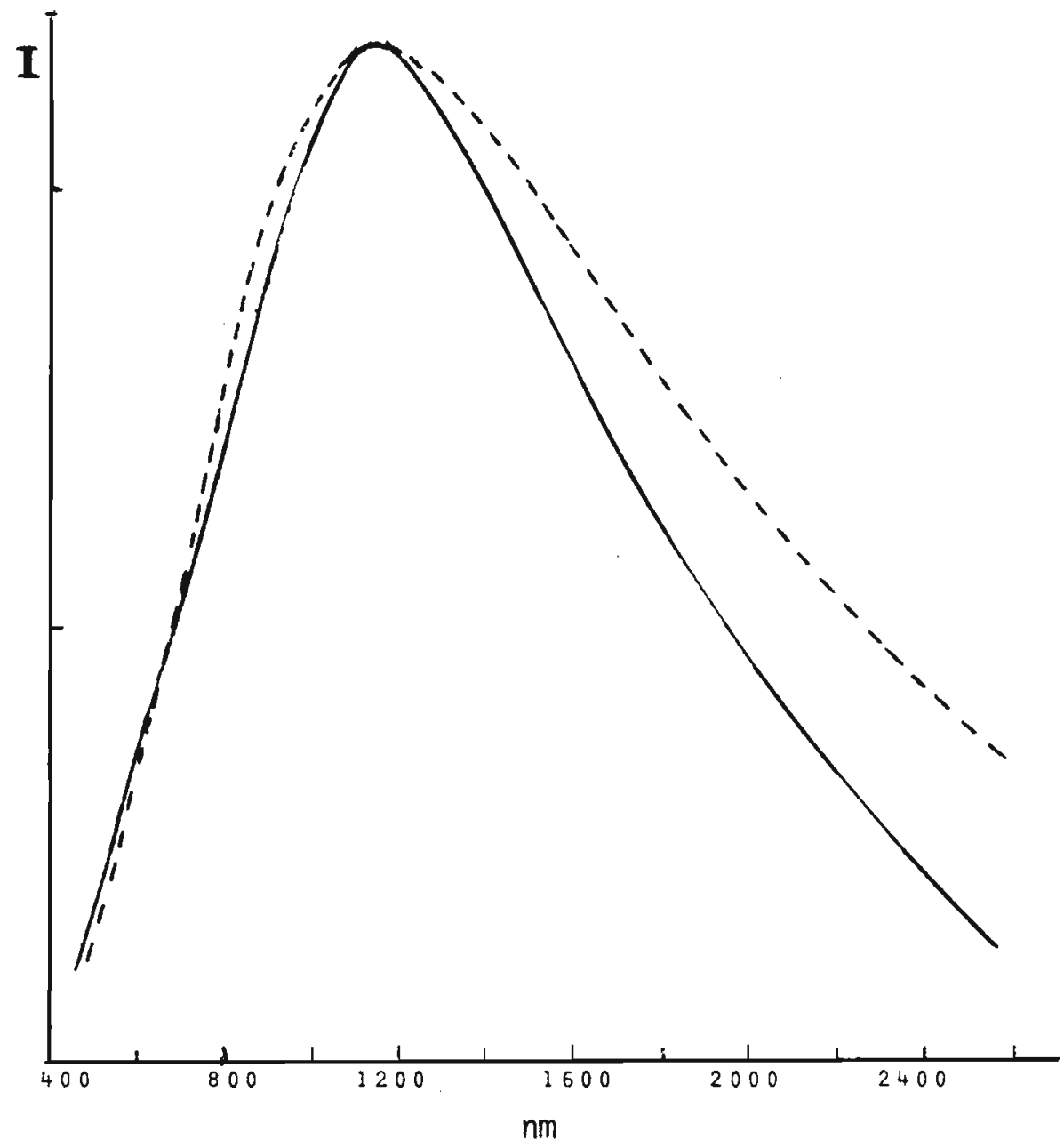

Figura 2.1. Curva de emissão de uma lāmpada de tungstēnio comparada com a de um corpo negro. - curva experimental;- - - curva de Planck para $T=2500 \mathrm{~K}$. Intensidade em escala arbitrāria. 
Com a lāmpada assim calibrada foi obtido o espectro no espectrōmetro Raman. Sendo a escala deste em nümero de onda e a monocromador Hilger em comprimento de onda, multiplicamos os valores de intensidade obtidos no espectrômetro Raman por $1 / \lambda^{2}$, desde que $\delta \nu=\left(1 / \lambda^{2}\right) \delta \lambda$. A razão entre a in tensidade da lâmpada padronizada e a deste espectro fornece a curva de correção, mostrada na Figura 2.2. Os valores de intensidade obtidos nos espectros Raman devem ser multiplicados pelos correspondentes valores desta curva. Na Figura 2.2 estão tambēm representadas as curvas de emissão espec tra1 da lâmpada e o espectro registrado no espectrómetro Ra man, para que se possa fazer uma comparação.

2.3. Largura espectral da fenda

Quando o espectrōmetro Raman não possue um servo me canismo que mantenha a largura da fenda espectral constante ao longo do espectro,outra correção deve ser introduzida, de vida a variação desta largura quando o valor da fenda mecā nica é fixado.

Este fator de correção pode ser determinado pela ex pressão que converte a largura da fenda mecânica $\Delta x, e m \mathrm{~cm}$, em largura de fenda espectral $\Delta V$, em $\mathrm{cm}^{-1}$ :

$$
\Delta V=\Delta X\left(V^{2} / F\right)\left(d^{2}-0,25 / V^{2}\right)^{1 / 2} \text {, }
$$

onde $V$ é o número de onda, $F \bar{e}$ a distância focal do duplo mo nocromador $(F=100 \mathrm{~cm})$ e dé o espaçamento entre os sulcos da rede $(d=1 / 11800 \mathrm{~cm})$. 


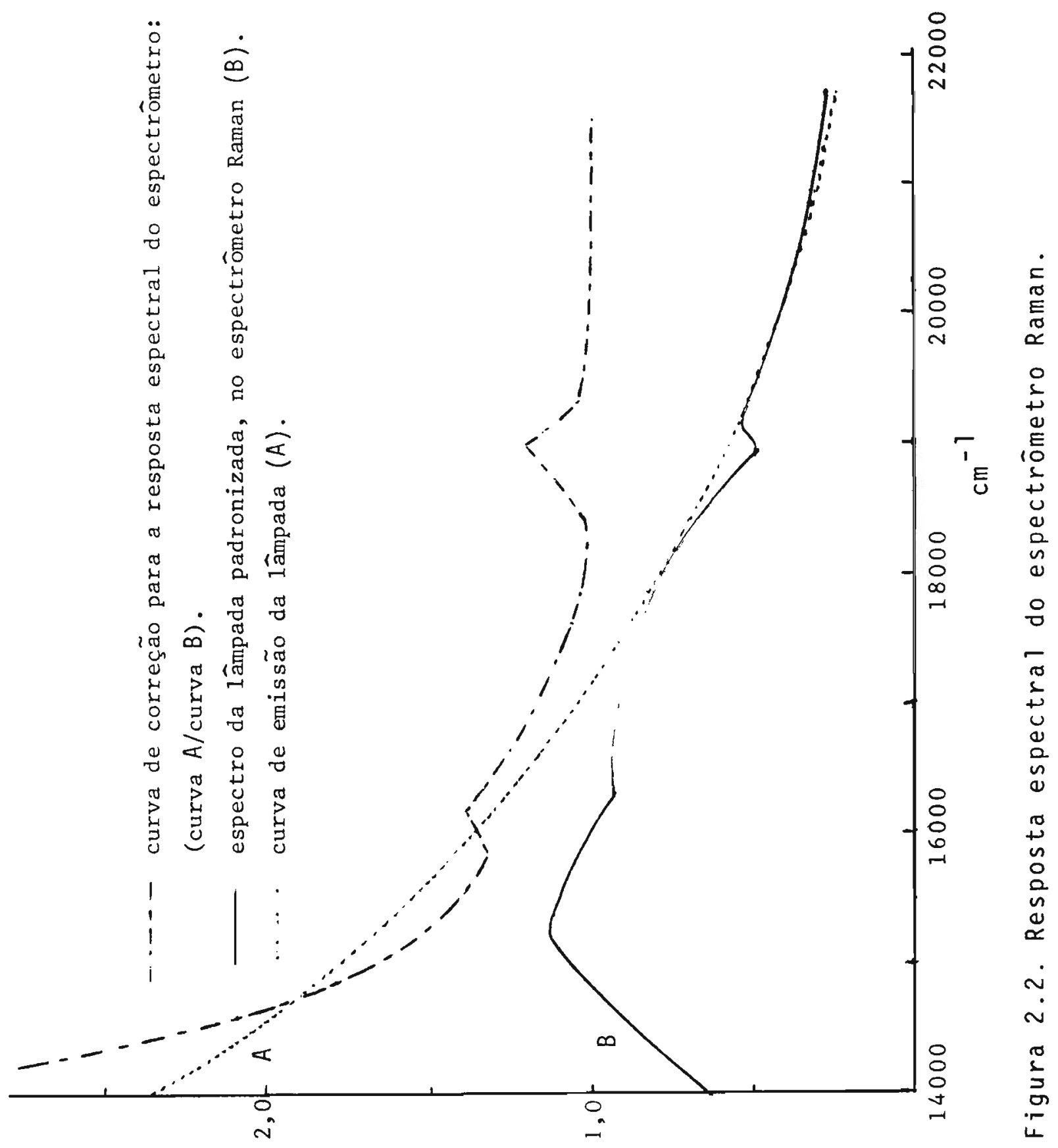


Os valores de intensidade nos espectros Raman devem ser divididos pelos correspondentes valores de $\Delta V$.

2.4. Padrão interno

Como indicador das condições do sistema de amostra e de iluminação, costuma-se usar um padrão interno nas medidas de intensidade relativa dos espectros Raman.

Na obtenção dos perfís de excitação, que dá a varia ção de intensidade de uma banda em função de diferentes fre quéncias de excitação, é evidente que este padrão interno não deverā apresentar efeito Raman ressonante. A escolha do padrão interno é as vezes dificultada pela presença de ban das que podem interferir no espectro.

No estudo do efeito Raman ressonante do $\mathrm{Cu}_{3} \mathrm{PS}_{4}$ e do $\mathrm{Ag}_{3} \mathrm{PS}_{4}$ usamos a banda em $148 \mathrm{~cm}^{-1}$ do $\mathrm{SrCO}_{3}$, como padrão, e pa ra 0 ion $\operatorname{Mos}_{4}{ }^{2-}$ usamos a banda em $1045 \mathrm{~cm}^{-1}$ do $\mathrm{NO}_{3}{ }^{-}$.

2.5. Medida de intensidade

A medida correta da intensidade de uma banda ē dada pela sua àrea. Entretanto, muitas vezes esta medida ē difí cil de ser efetuada devida a sobreposição parcial de diferen tes bandas. Quando isto ocorre podemos considerar a medida da altura do pico da banda como valor de sua intensidade, o que pode ser feito desde que não haja variação da meia lar gura da banda. E o caso quando comparamos a intensidade de uma mesma banda em diferentes excitações. Se compararmos a 
intensidade de uma mesma banda em diferentes temperaturas e ta aproximação jā não è mais vāilida, pois haverá variação da meia largura.

No estudo dos compostos $\mathrm{Cu}_{3} \mathrm{PS}_{4}, \mathrm{Ag}_{3} \mathrm{PS}_{4}$ e do Ton $\operatorname{MoS}_{4}{ }^{2-}$, em temperatura ambiente, utilizamos a medida da altu ra do pico como valor da intensidade. No estudo do $\mathrm{Cu}_{3} \mathrm{PS}_{4}$, em temperatura de $\mathrm{N}_{2}$ líquido e com variação da temperatura, uti lizamos como valor de intensidade as medidas de área, obtidas com um planimetro. Somente intensidades relativas são cons $\underline{i}$ deradas neste trabalho. 


$$
\text { CAPITULO } 3
$$

Cu $_{3}$ PS $_{4}$ : Espectro vibracional e atribuição das frequências Espectro Raman ressonante.

\subsection{Introdução}

Para os sais de tiofosfatos somente o espectro vi bracional do $\mathrm{Na}_{3} \mathrm{PS}_{4}$ era conhecido ${ }^{1}$. Por outro lado, os tra balhos sobre Raman ressonante de frequencias fundamentais eram limitados a líquidos ou soluções, pela dificuldade de se avaliar o efeito de absorção da luz em sōlidos policrís talinos. Neste capĩtulo apresentamos um método que desen volvemos para avaliação desse efeito, através dos espectros Raman. Discutiremos uma atribuição de frequẽncias para o es pectro vibracional do $\mathrm{Cu}_{3} \mathrm{PS}_{4}$ no estado sölido, os perfís de excitação dos modos internos, em temperatura ambiente e de nitrogēnio līquido, e consideraremos o efeito da variação de temperatura na intensidade de algumas bandas.

\subsection{Parte experimental}

O tiofosfato de cobre foi preparado conforme ind cação na literatura ${ }^{2}$, pelo aquecimento tanto do cloreto de cobre(I) como do cloreto de cobre(II) com excesso de penta sulfeto de fósforo $\left(\mathrm{P}_{2} \mathrm{~S}_{5}\right)$, em atmosfera inerte. 0 aqueci mento em temperatura mais elevada $\left(-500^{\circ} \mathrm{C}\right)$, durante meia 
hora, produz um composto de cor amarela, ma is clara do que o obtido por aquecimento mais brando $\left(-300^{\circ} \mathrm{C}\right)$. 0 excesso de ${ }_{2} \mathrm{~S}_{5} \overline{\mathrm{e}}$ destilado para fora do tubo de reação. 0 produto ob tido, apōs lavagem com solução diluida de ácido cloridico a quente, agua e alcool, é secado em vácuo. o composto mos trou-se insolūvel em todos solventes experimentados. Os es pectros Raman e infravermelho das amostras obtidas de CuCl ou de $\mathrm{CuCl}_{2}$ foram idênticos. Os espectros de absorção no infravermelho se mostraram mais sensiveis à presença de im purezas provenientes da hidrólise do $\mathrm{P}_{2} \mathrm{~S}_{5}$ usado na prepara ção. Os espectros Raman das amostras obtidas com maior a quecimento foram de muito melhor qualidade. A anālise ele mentar do cobre utilizando método de titulação com EDTA a presentou desvio de $3 \%$ em relação ao teōrico.

os espectros Raman foram registrados no espectrōme tro Raman Jarrell-Ash, 25-300, utilizando-se as radiações 647,1 e 568,2 nm de um laser de $\mathrm{Kr}^{+}$e 514,5, 496,5, 488,0, 476,5 e $457,9 \mathrm{~nm}$ de um laser de $\mathrm{Ar}^{+}$. A potência destas ra diações foi mantida menor de $30 \mathrm{~mW}$, para evitar decomposi ção da amostra. Os espectros em temperatura ambiente foram obtidos usando cela rotatōria ${ }^{3}$ e os espectros em baixa tem peratura, numa cela convencional com dedo frio. 0 s espec tros com variação de temperatura foram obtidos regulando se o fluxo de nitrogênio evaporado de $\mathrm{N}_{2}$ liquido, que re frigerava o dedo frio da cela. A temperatura do suporte da amostra era determinada por um par termoelétrico previamen 
te calibrado. Os espectros Raman em baixa temperatura apre sentaram melhor relação sinal/ruido.

Foram obtidos espectros Raman da amostra pura, da amostra formando uma mistura homogēnea com o padrão ( $\left.\mathrm{SrCO}_{3}\right)$ e da amostra e padrão colocados separadamente em setores al ternados de um disco em rotação. Estes setores podiam ser

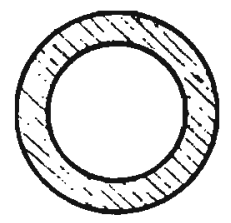

amostra homogênea

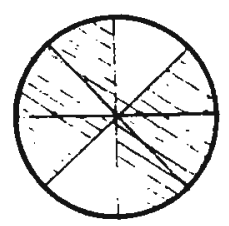

amostra em setor preenchidos numa proporção tal, de forma a dar uma rela ção de intensidade entre as 1 inhas do $\mathrm{SrCO}_{3}$ e $\mathrm{Cu}_{3} \mathrm{PS}_{4}$ se melhante à obtida com a mís tura homogénea. Por exemplo, uma mistura de $60: 1\left(\mathrm{SrCO}_{3} / \mathrm{Cu}_{3} \mathrm{PS}_{4}\right)$ correspondia a uma rela ção de āreas dos setores de 1:3. A maior percentagem de $\mathrm{SrCO}_{3}$ na mistura homogênea é necessāria para compensar a perda de intensidade, no espectro do $\mathrm{SrCO}_{3}$, devida à absor ção pelo $\mathrm{Cu}_{3} \mathrm{PS}_{4}$.

os espectros de absorção no infravermelho foram ob tidos no espectrofotómetro Perkin-Elmer 180, usando pasta com Nujol entre placas de CsI ou de polietileno. Foram ob tidos espectros em temperatura ambiente e de $\mathrm{N}_{2}$ liquido.

Na Figura 3.1 são comparados os espectros Raman do $\mathrm{Cu}_{3} \mathrm{PS}_{4}$ em temperatura ambiente e de $\mathrm{N}_{2} 1 \mathrm{iquido}$, excitados pela radiação $514,5 \mathrm{~nm}$ do laser de $\mathrm{Ar}^{+}$. Na Figura 3.2 são comparados os espectros no infravermelho, em temperatura ambiente e de $\mathrm{N}_{2}$ líquido. 


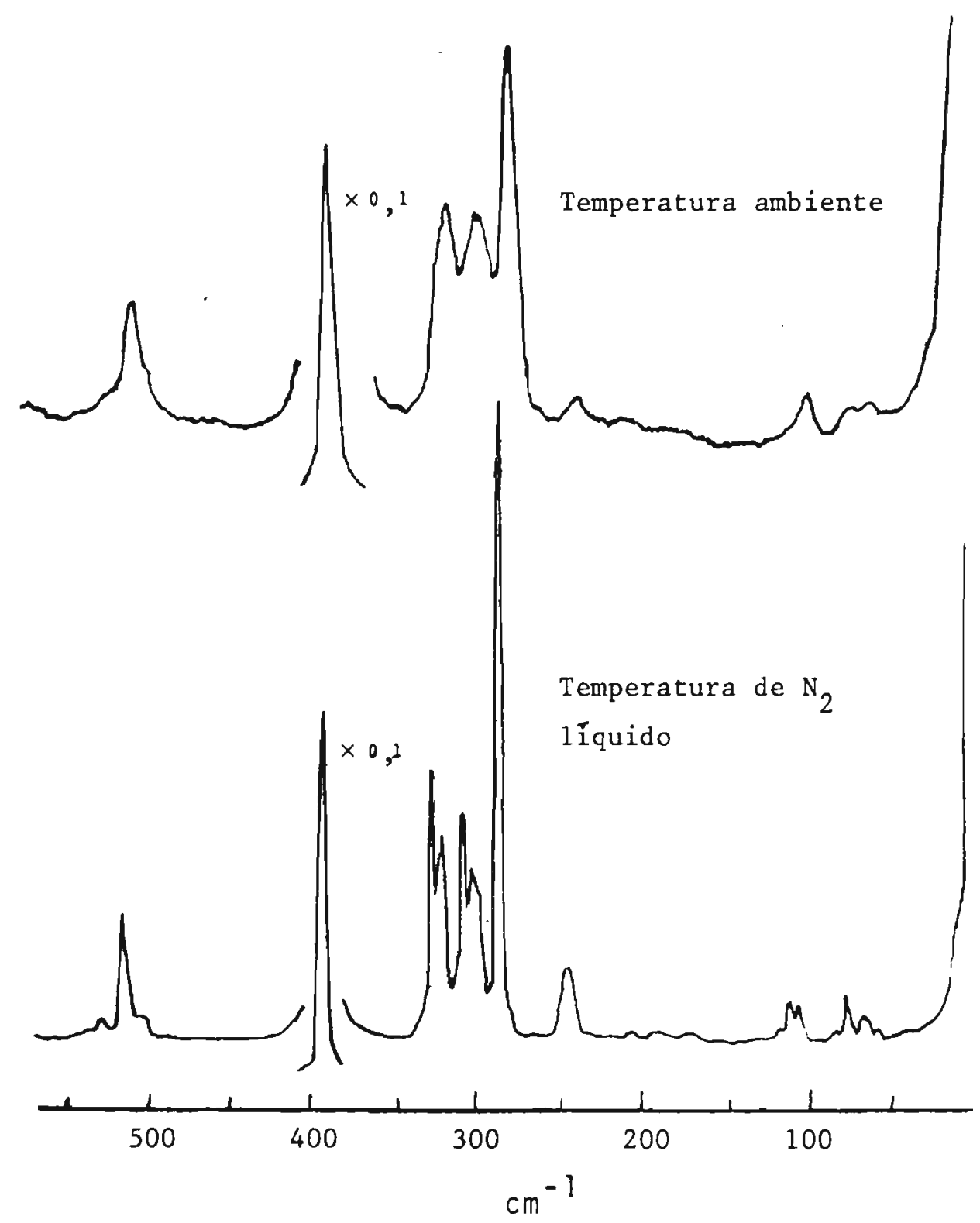

Figura 3.1. Espectros Raman do $\mathrm{Cu}_{3} \mathrm{PS}_{4}$ excitados pela radiação $514,5 \mathrm{~nm}$ de um laser de $\mathrm{Ar}^{+}$.Obser va-se o desdobramento de algumas bandas, em ba $\underline{i}$ xa temperatura. 

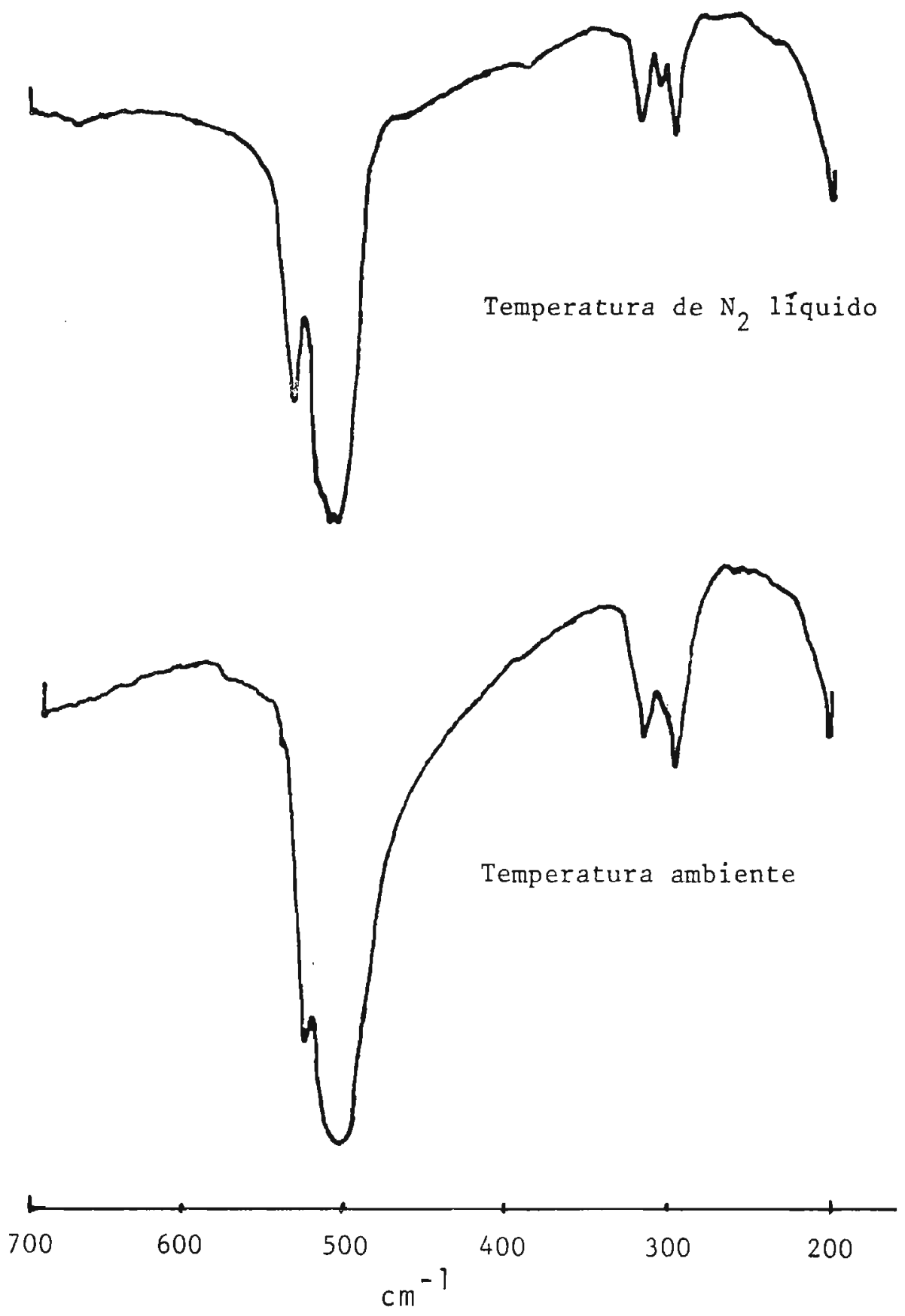

Figura 3.2. Espectros de absorção no infravermelho, do $\mathrm{Cu}_{3} \mathrm{PS}_{4}$. 


\subsection{Atribuição das frequēncias}

De acordo com os dados de raio- $x^{4,5}$, o grupo de es paço do $\mathrm{Cu}_{3} \mathrm{PS}_{4} \overline{\mathrm{e}}$ o $\mathrm{C}_{2 \mathrm{v}}^{7}\left(\mathrm{Pmn}_{1}\right)$, com duas moléculas por ce la unitāria. A anālise do grupo de fator, pelo método das correlações $^{6}$, nos levou à representação mostrada na Tabela 3.1 .

TABELA 3. I.

Anālise de grupo de fator para $0 \mathrm{Cu}_{3} \mathrm{PS}_{4}$.

\begin{tabular}{llllll}
$C_{2 V}$ & $N$ & $T^{\prime}$ & $T$ & $R$ & $n$ \\
\hline$A_{1}$ & 14 & 1 & 6 & 1 & 6 \\
$A_{2}$ & 10 & 0 & 5 & 2 & 3 \\
$B_{1}$ & 10 & 1 & 4 & 2 & 3 \\
$B_{2}$ & 14 & 1 & 6 & 1 & 6 \\
\hline
\end{tabular}

$N=$ número total de modos vibracionais do cristal.

$T^{\prime}=$ número de modos acústicos (translação da cela unitāria)

$T=$ número de modos externos do tipo translação (translações da rede).

$\mathrm{R}=$ nümero de modos externos do tipo rotação (librações).

$n=$ número de modos internos.

Deveríamos, portanto, esperar 18 modos internos, mas somente 9 foram observados. A razão disto fica clara se considerarmos a simetria local ("site") no cristal. Para o ion $\mathrm{PS}_{4}{ }^{3-}$ a simetria do ion isolado $\overline{\mathrm{e}} \mathrm{T}_{\mathrm{d}}\left(\Gamma=\mathrm{A}_{1}+E+2 \mathrm{~F}_{2}\right)$, mas 
a simetria local e $C_{s}$. Pela correlação entre esses grupos as 4 frequéncias do grupo $T_{d}$ se desdobram em 9 frequéncias, $6 A^{\prime}$ e $3 A^{\prime \prime}$ do grupo $C_{S}$, somente por desdobramento de campo estātico (desdobramento de grupo local), que é uma medida da influência da rede cristalina que envolve o ion. Este cam po acarreta rompimento da degenerescéncia. Havendo duas mo léculas na cela de Bravais a simetria desta e $C_{2 v}^{7}$, devendo ser correlacionada com o grupo local, cujo número de frequên cias deve ser agora multiplicado por 2 (duas moléculas na cela). As 12 frequências $A^{\prime}\left(C_{S}\right)$ se correlacionam com as es pécies $A_{1}$ e $B_{2}\left(C_{2 v}\right)$ e as 6 frequéncias $A^{\prime \prime}$, com as espēci es $A_{2}$ e $B_{1}$. Este desdobramento pelo campo de correlação é devido a interação com vibrações internas de outras molécu las na mesma cela unitāria. O desdobramento resultante do campo estātico e do campo de correlação é chamado desdobramento de grupo de fator.

Desde que foram observadas somente 9 frequēncias., concluimos que a interação entre as vibrações internas dos ions $\mathrm{PS}_{4}{ }^{3-}$ numa mesma cela é desprezivel, acarretando uma degenerescēncia acidental. Assim, não podemos separar as fré quências de espécie $A_{1}$ e $B_{2}$, o mesmo acontecendo com as fre quências de espécie $A_{2}$ e $B_{1}$. Na atribuição elas serão indi cadas por $A_{1}+B_{2}$ e por $A_{2}+B_{1}$, respectivamente, com 6 frequēn cias observadas no primeiro caso e 3 no $\bar{u} 1$ timo.

A correlação entre os grupos $T_{d}$ (íon livre), $C_{s}$ (gru 
po local) e $c_{2 v}^{7}$ (cela unitāria) pode ser resumida no esque ma abaixo, estando indicado à direita o nümero de vibrações para 1 ion e à esquerda o número considerando os 2 ions na cela unitāria.

$$
c_{2 v}^{7}
$$

$\mathrm{c}_{\mathrm{s}}$

$T_{d}$

(6)<smiles></smiles>

(3)

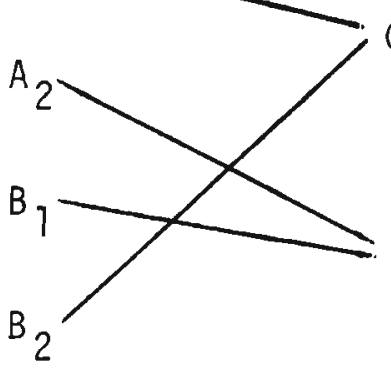

(12) $A^{\prime}(6)$

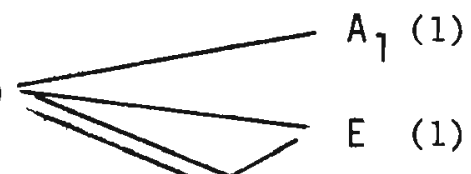

(3)

(6) $\mathrm{B}_{2}$

(6) $A^{\prime \prime}(3)$

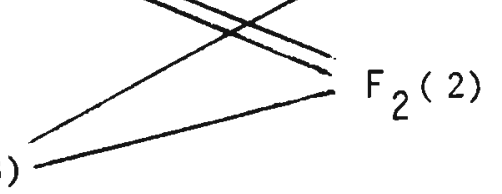

Na Tabela 3.II estão os valores das frequências ob servadas, Raman e infravermelho, em temperatura ambiente e de $\mathrm{N}_{2}$ liquido.

Na Figura 3.3 são comparados os espectros Raman e infraverme1ho, temperatura ambiente, na região das frequên cias fundamentais, podendo-se observar a conservação das regras de seleção do ion livre, simetria $T_{d}$, onde as vibra ções de espēcie $A_{1}$ e $E$ são ativas somente no Raman e as de espécie $F_{2}$ são ativas no Raman e no infravermelho. Nota-se - desdobramento de campo estático das bandas de espécie $F_{2}$, contudo, não completamente resolvidas, devido ao alargamen to das bandas na temperatura ambiente.

Por comparação com os espectros do $\mathrm{Na}_{3} \mathrm{PS}_{4}{ }^{1}$, pelas 
TABELA 3. II.

Valores das frequências observadas $\left(\mathrm{cm}^{-1}\right)$ nos espectros Raman e infravermelho, a $300 \mathrm{~K}$ e a $100 \mathrm{~K}$.

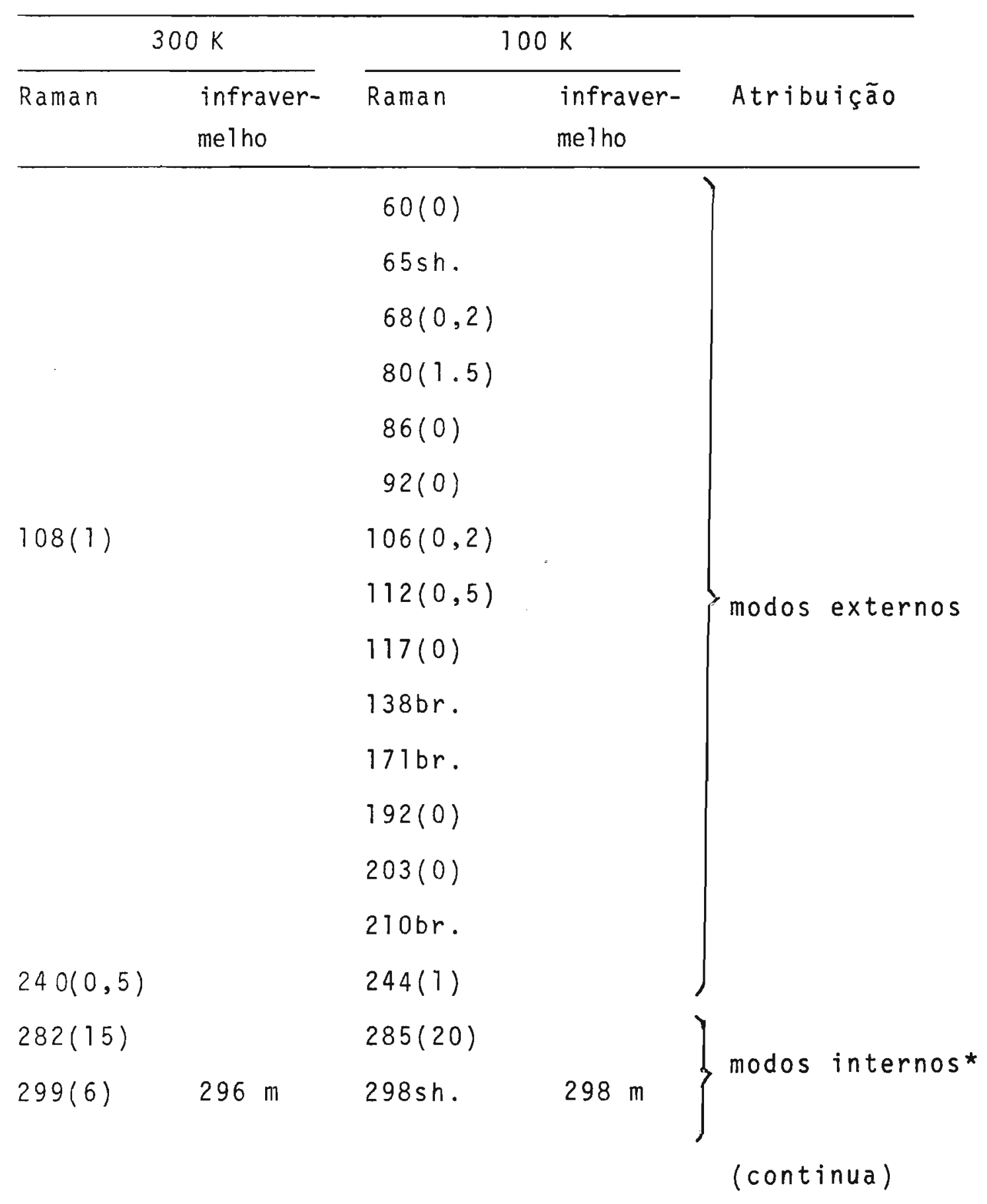


TABELA 3.II. (continuação)

\begin{tabular}{|c|c|c|c|c|}
\hline \multicolumn{2}{|c|}{$300 \mathrm{~K}$} & \multicolumn{2}{|c|}{$100 \mathrm{~K}$} & \multirow[b]{2}{*}{ Atribuição } \\
\hline Raman & $\begin{array}{l}\text { infraver- } \\
\text { melho }\end{array}$ & Raman & $\begin{array}{l}\text { infraver- } \\
\text { mel ho }\end{array}$ & \\
\hline & & $300(2)$ & & \\
\hline & & $307(4)$ & $308 w$ & \\
\hline \multirow[t]{2}{*}{$318(6)$} & $317 \mathrm{~m}$ & $320(3)$ & $321 \mathrm{~m}$ & modos internos* \\
\hline & & $326(2,5)$ & & \\
\hline \multirow[t]{4}{*}{$391(100)$} & & $392(100)$ & & $v_{1}$ \\
\hline & & $462(0,3)$ & & $v_{1}+68$ \\
\hline & & $488 \mathrm{br}$ & & $v_{1}+92$ \\
\hline & & $500(0,5)$ & & $v_{1}+106$ \\
\hline \multirow[t]{10}{*}{$511(2)$} & 512 vs & $512(3)$ & $\begin{array}{l}510 \mathrm{VS} \\
515 \mathrm{VS}\end{array}$ & Imodos internos* \\
\hline & & & $523 \mathrm{sh}$ & \\
\hline & & $528(0,5)$ & & $v_{1}+138$ \\
\hline & $535 \mathrm{~ms}$ & $539 b r$ & $539 \mathrm{~ms}$ & modo interno* \\
\hline & & $575(0,5)$ & & $2 \times 286$ \\
\hline & & $585 \mathrm{br}$ & & $v_{1}+192$ \\
\hline & & $595(0,5)$ & & $v_{7}+203$ \\
\hline & & 677 & & $v_{1}+285$ \\
\hline & & 693 & & $v_{1}+300$ \\
\hline & & 713 & & $v_{1}+320$ \\
\hline \multirow[t]{2}{*}{780} & & 784 & & $2 v_{1}$ \\
\hline & & 856 & & $\begin{array}{l}2 v_{1}+68 \\
\text { (continua). }\end{array}$ \\
\hline
\end{tabular}


TABELA 3.II. (continuação)

\begin{tabular}{|c|c|c|c|c|}
\hline \multicolumn{2}{|c|}{$300 \mathrm{~K}$} & \multicolumn{2}{|c|}{$100 \mathrm{~K}$} & \multirow[b]{2}{*}{ Atribuição } \\
\hline Raman & $\begin{array}{l}\text { infraver- } \\
\text { melho }\end{array}$ & Raman & $\begin{array}{l}\text { infraver- } \\
\text { melho }\end{array}$ & \\
\hline & & 889 & & $2 v_{1}+106$ \\
\hline & & 908 & & $v_{1}+512$ \\
\hline & & 915 & & $v_{1}+523 ; 2 v_{1}+138$ \\
\hline & & 980 & & $2 v_{1}+\left\{\begin{array}{lll}1 & 9 & 2 \\
2 & 0 & 3\end{array}\right.$ \\
\hline & & 1072 & & $2 v_{1}+285$ \\
\hline & & 1083 & & $2 v_{1}+300$ \\
\hline & & 1103 & & $2 v_{1}+320$ \\
\hline \multirow[t]{7}{*}{1167} & & 1175 & & $3 \nu_{1}$ \\
\hline & & 1248 & & $3 v_{1}+ \begin{cases}6 & 8 \\
8 & 0\end{cases}$ \\
\hline & & 1278 & & $3 v_{1}+106$ \\
\hline & & 1302 & & $2 v_{1}+\left\{\begin{array}{lll}5 & 1 & 2\end{array} ; 33 v_{1}+13\right.$ \\
\hline & & 1370 & & $3 v_{1}+\left\{\begin{array}{lll}1 & 2 & 0 \\
3\end{array}\right.$ \\
\hline & & 1465 & & $24\left\{\begin{array}{llll}2 & 8 & 5 \\
3 & 0 & 0\end{array}\right.$ \\
\hline & & 1493 & & $17[320$ \\
\hline \multirow[t]{6}{*}{1550} & & 1565 & & $4 v_{1}$ \\
\hline & & 1643 & & $4 \nu_{1}+\left\{\begin{array}{lll}8 & 0\end{array}\right.$ \\
\hline & & 1670 & & $4 v_{1}+106$ \\
\hline & & 1755 & & $4 v_{1}+\left\{\begin{array}{lll}1 & 9 & 2 \\
2 & 0 & 3\end{array}\right.$ \\
\hline & & 1853 & & $4 \nu \nu_{1}+\left\{\begin{array}{lll}2 & 8 & 5 \\
3 & 0 & 0\end{array}\right.$ \\
\hline & & 1883 & & $\begin{array}{l}4 v_{1}+320 \\
\text { (continua) }\end{array}$ \\
\hline
\end{tabular}


TABELA 3.II. (continuação)

\begin{tabular}{|c|c|c|c|c|}
\hline \multicolumn{2}{|c|}{$300 \mathrm{~K}$} & \multicolumn{2}{|c|}{$100 \mathrm{~K}$} & \multirow[b]{2}{*}{ Atribuição } \\
\hline Raman & $\begin{array}{l}\text { infraver- } \\
\text { melho }\end{array}$ & Raman & $\begin{array}{l}\text { infraver- } \\
\text { mel ho }\end{array}$ & \\
\hline & & 1953 & & $5 v_{1}$ \\
\hline & & 2032 & & $5 v_{1}+ \begin{cases}8 & 0 \\
6 & 8\end{cases}$ \\
\hline & & 2058 & & $5 v_{1}+106$ \\
\hline & & 2090 & & $4 v_{1}+523 ; 5 v_{1}+138$ \\
\hline & & 2148 & & $5 v_{1}+\begin{array}{lll}1 & 9 & 2 \\
2 & 0 & 3\end{array}$ \\
\hline & & 2245 & & $5 v_{1}+\left\{\begin{array}{lll}2 & 8 & 6 \\
3 & 0 & 0 \\
3 & 2 & 0\end{array}\right.$ \\
\hline & & 2340 & & $6 v_{1}$ \\
\hline & & 2433 & & $6 v_{1}+\left\{\begin{array}{lll}6 & 8 \\
1 & 0 & 0\end{array}\right.$ \\
\hline & & 2538 & & $6 v_{1}+\left\{\begin{array}{lll}1 & 9 & 2 \\
2 & 0 & 3\end{array}\right.$ \\
\hline & & 2635 & & $6 v_{1}+\left\{\begin{array}{lll}2 & 8 & 5 \\
3 & 0 & 0 \\
3 & 2 & 0\end{array}\right.$ \\
\hline & & 2727 & & $7 v_{1}$ \\
\hline & & 3112 & & $8 v_{1}$ \\
\hline & & 3499 & & $9 v_{1}$ \\
\hline
\end{tabular}

* V. texto para a atribuição dos modos internos.

$\nu_{1}$ representa o estiramento simétrico $\nu(P-S)$ 


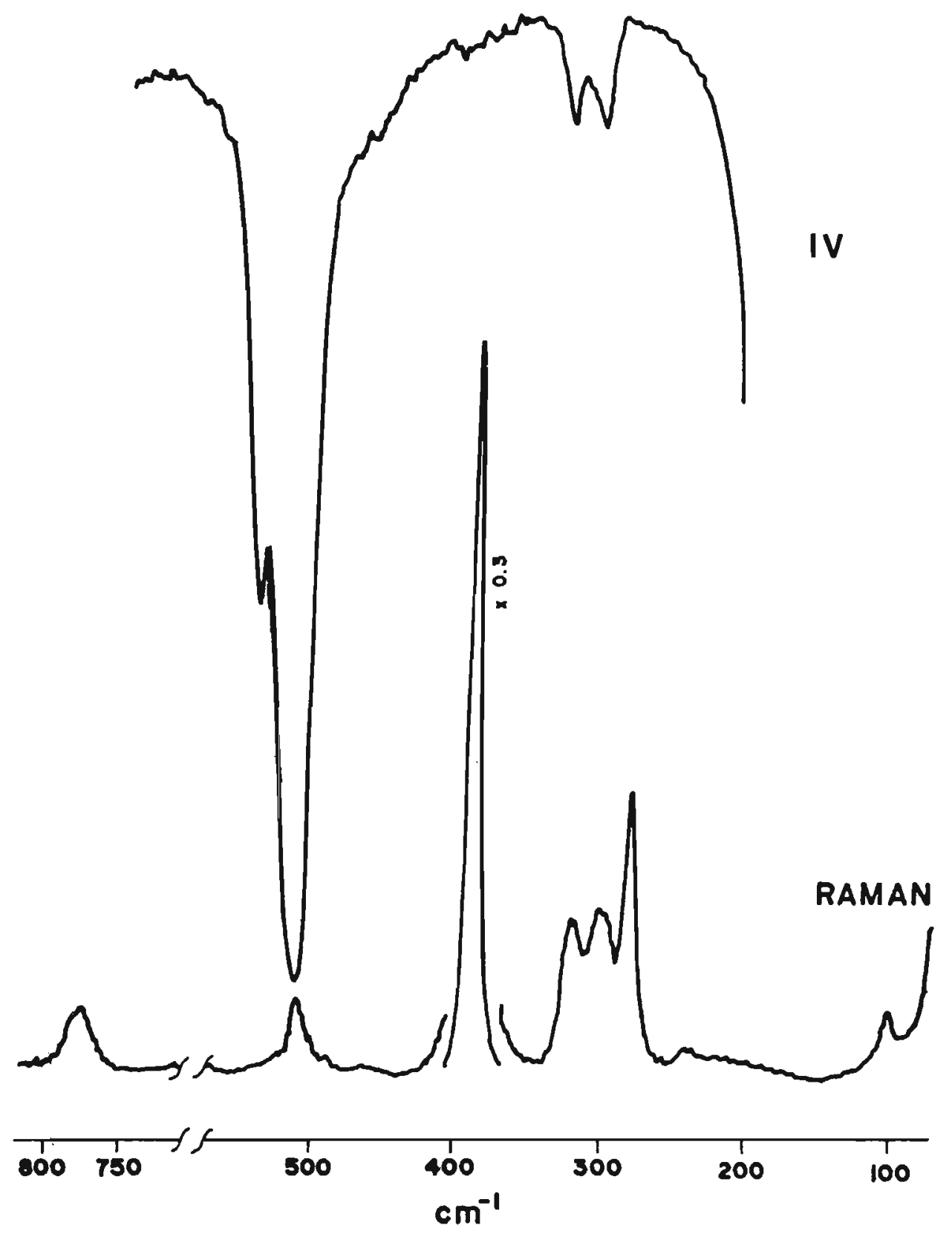

Figura 3.3. Espectros infravermelho e Raman, tempe ratura ambiente, do $\mathrm{Cu}_{3} \mathrm{PS}_{4}$. 
intensidades relativas das bandas e ainda pela ordem de grandeza das massas atomicas envolvidas, podemos distin guir facilmente a região das frequéncias de rede ( abaixo de $250 \mathrm{~cm}^{-1}$ ) da região dos modos internos do $\mathrm{PS}_{4}^{3-}$ (250 a $\left.550 \mathrm{~cm}^{-1}\right)$.

Sem o emprego de um monocristal orientado de $\mathrm{Cu}_{3} \mathrm{PS}_{4}$ qualquer tentativa de atribuição das frequências Ra man dos modos externos seria puramente especulativa. Dado - grande nūmero destas frequēncias num intervalo espectral estreito (V. Tabela 3.II), mesmo o cālculo de coordenadas normais seria extremamente dificil, pela mistura devida aos acoplamentos envolvidos.

observando os espectros da Figura 3.3, devido à $\underline{a}$ tividade Raman e ifafravermelho podemos pensar nos modos in ternos em termos do ion $\mathrm{PS}_{4}{ }^{3-} 1$ ivre $\left(T_{d}\right)$, como ponto de partida para uma atribuição.

Pela sua intensidade forte no Raman e auséncia no infraverme 1 ho a banda em $-390 \mathrm{~cm}^{-1}$ seria atribuida ao es tiramento $v(P-S)$ simétrico; a banda Raman em $\sim 280 \mathrm{~cm}^{-1}$, a $\underline{u}$ sente no infravermelho, seria atribuida a deformação de ãn gulo de espēcie E; a banda intensa no infravermelho em $510 \mathrm{~cm}^{-1}$, relativamente fraca no Raman, seria atribuida ao estiramento $v(P-S)$ de espēcie $F_{2}$; as bandas em $\sim 300$ e 320 $\mathrm{cm}^{-1}$, ativas no Raman e infravermelho, seriam atribuidas à deformação de àngulo de espécie $F_{2}$, com quebra parcial 
da degenerescēncia.

A rigor, a atribuição deve ser feita para o grupo de fator $C_{2 v}$, embora os espectros indiquem que a distorção do ion no cristal seja pequena, isto $\bar{e}$, suficiente para romper a degenerescéncia mas não para modificar as regras de seleção. Poderiamos considerar 4 conjuntos de atribuições, levando em conta as considerações feitas até agora:

I I I I I IV

392

$$
\left(A_{1}+B_{2}\right) \quad\left(A_{1}+B_{2}\right) \quad 392 \quad\left(A_{1}+B_{2}\right) \quad\left(A_{1}+B_{2}\right)
$$

285

$\left(A_{1}+B_{2}\right) \quad\left(A_{1}+B_{2}\right)$

285

$\left(A_{1}+B_{2}\right) \quad\left(A_{1}+B_{2}\right)$

298

$\left(A_{2}+B_{1}\right) \quad\left(A_{2}+B_{1}\right)$

300

$\left(A_{2}+B_{1}\right) \quad\left(A_{2}+B_{1}\right)$

$512 \quad\left(A_{1}+B_{2}\right) \quad\left(A_{2}+B_{1}\right)$

$512 \quad\left(A_{1}+B_{2}\right) \quad\left(A_{2}+B_{1}\right)$

$523 \quad\left(A_{2}+B_{1}\right) \quad\left(A_{1}+B_{2}\right)$

$523 \quad\left(A_{2}+B_{1}\right) \quad\left(A_{1}+B_{2}\right)$

$539 \quad\left(A_{1}+B_{2}\right) \quad\left(A_{1}+B_{2}\right)$

$539 \quad\left(A_{1}+B_{2}\right) \quad\left(A_{1}+B_{2}\right)$

$320 \quad\left(A_{1}+B_{2}\right) \quad\left(A_{1}+B_{2}\right)$

$320 \quad\left(A_{1}+B_{2}\right) \quad\left(A_{1}+B_{2}\right)$

$307 \quad\left(A_{1}+B_{2}\right) \quad\left(A_{2}+B_{1}\right)$

$307 \quad\left(A_{1}+B_{2}\right) \quad\left(A_{2}+B_{1}\right)$

$300 \quad\left(A_{2}+B_{1}\right) \quad\left(A_{1}+B_{2}\right)$

$300 \quad\left(A_{2}+B_{1}\right) \quad\left(A_{1}+B_{2}\right)$

A diferença de apenas $2 \mathrm{~cm}^{-1}$ entre as frequēncias Raman 298 e $300 \mathrm{~cm}^{-1}$ torna dificil decidir qual delas é a coincidente com o valor observado no infravermelho, 298 $\mathrm{cm}^{-1}$, pois esta coincidēncia não é numericamente signifi cativa, estando dentro da diferença normalmente observada entre os espectros Raman e infravermelho. Nos 4 conjuntos 
apresentados a diferença entre os dois primeiros e os dois ūitimos está somente na escolha da coincidência da banda no infravermelho com a $300 \mathrm{~cm}^{-1}$ ou a $298 \mathrm{~cm}^{-1}$. Entre os con juntos I e II e entre os conjuntos II e IV a diferença es tā essencialmente na escolha da $512 \mathrm{~cm}^{-1}$ e da $307 \mathrm{~cm}^{-1}$ co mo $\left(A_{1}+B_{2}\right)$ ou como $\left(A_{2}+B_{1}\right)$, a atribuição das restantes sen do uma consequéncia dessa escolha.

Adiantando os resultados obtidos no estudo do efei to Raman ressonante que faremos adiante, com a obtenção do perfīl de excitação, nossa escolha estā entre o conjunto I ou III, atribuindo as bandas que apresentam maior ressonān cia para a espēcie $\left(A_{1}+B_{2}\right)$.

3.4. Variação da intensidade das bandas Raman com a tempe ratura.

Observamos nos espectros Raman em baixa temperatura maior número de bandas do que em temperatura ambiente, a 1 ém de pronunciada variação na altura do pico de algumas bandas. Uma explicação possível para esse fato seria a de existir uma transição de fase. Com a finalidade de verificar esta hipótese obtivemos uma serie de espectros Raman vari ando a temperatura de $300 \mathrm{~K}$ a $100 \mathrm{~K}$, em intervalos de 10 a 20 graus, dependendo da variação apresentada no espectro.

$\mathrm{Na}$ obtenção destes espectros notamos que uma peque na variação da potência do laser produzia sensĩvel varia ção na temperatura local da amostra, traduzida na resolução 
das bandas. Para minimizar este aquecimento utilizamos uma lente cilindrica de modo a diminuir a densidade de radia ção do feixe do laser na amostra, desde que na cela de ba $\underline{i}$ xa temperatura não temos um sistema rotatōrio.

os espectros mostraram que as bandas dos modos in ternos começam a se desdobrar quando a temperatura è aba xada ao redor de $250 \mathrm{~K}$ e que ao redor de $200 \mathrm{~K}$ começam a parecer mais bandas de modos externos. Como outros fatores podiam tambēm ser levados em consideração na explicação do fenōmeno observado, não pudemos concluir através dos espec tros se ocorria ou não uma transição de fase. obtivemos tam bēm difratogramas de raio-x nas temperaturas de 300 e de $100 \mathrm{k}$, que foram idēnticos, não indicando, portanto, ocor rência de transição,de fase.

0 efeito da temperatura nos espectros deve estar relacionado com a melhor razão sinal/ruido e ao estreitamen to das bandas (e consequente aumento da altura do pico) em baixas temperaturas.

Medindo a intensidade pela ārea das bandas, fizemos - levantamento da curva de variação da intensidade em fun ção da temperatura para as bandas de modos externos em 106 e em $244 \mathrm{~cm}^{-1}$, dos modos internos 285 e $392 \mathrm{~cm}^{-1}$ e da har mōnica da $392 \mathrm{~cm}^{-1}$, em $784 \mathrm{~cm}^{-1}$. A escolha dessas bandas $\bar{e}$ por elas serem isoladas ou com menor sobreposição com ban vizinhas.Usamos como padrão interno a banda $148 \mathrm{~cm}^{-1}$ do $\mathrm{SrCO}_{3}$, que constatamos previamente não sofrer modificação 
por efeito de temperatura. Na Figura 3.4 estā representada esta variação de intensidade em função da temperatura.

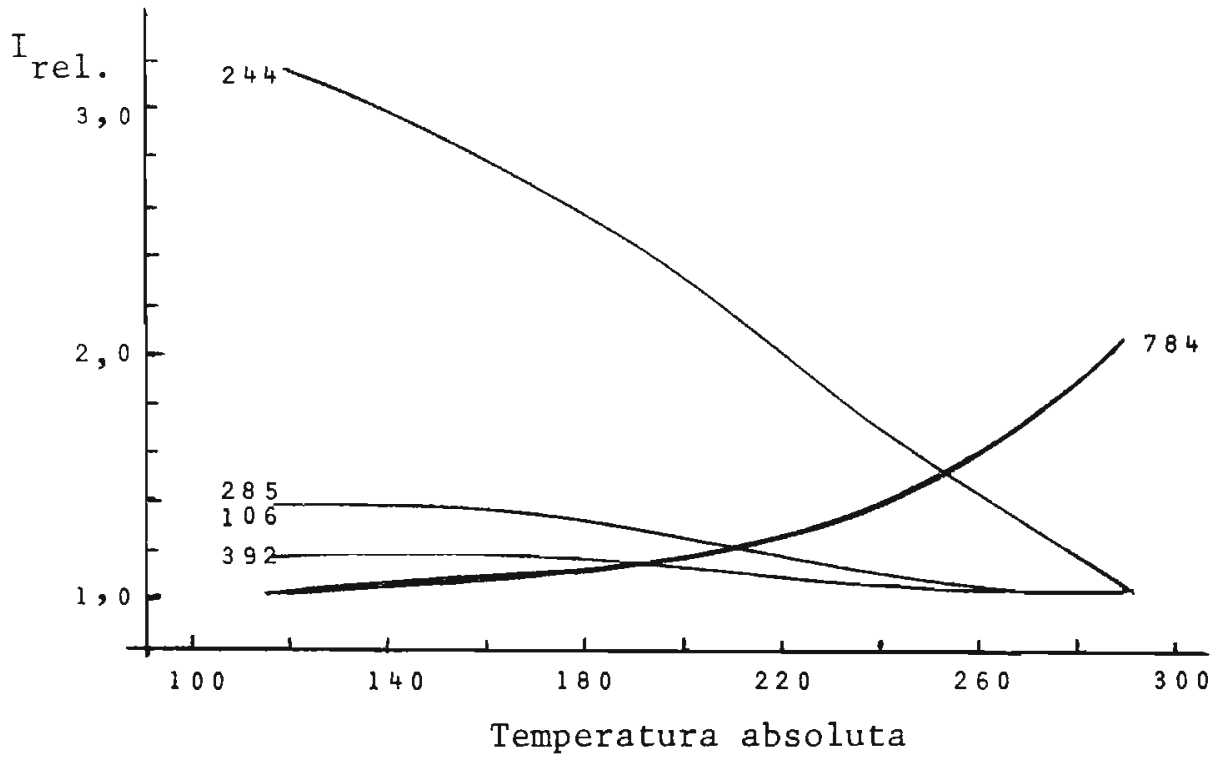

Figura 3.4. Variação da intensidade relativa em função da temperatura para as frequências indicadas.

Nesta Figura observa-se para os modos internos um pequeno aumento da intensidade com o abaixamento da tempe ratura, até aproximadamente $230 \mathrm{~K}$, permanecendo depois esta cionārio. Para a harmōnica observa-se, pelo contrārio, uma diminuição de intensidade com o abaixamento da temperatura. 0 modo externo em $244 \mathrm{~cm}^{-1}$ apresenta maior variação de in tensidade do que 0 modo em $106 \mathrm{~cm}^{-1}$.

A sensĩvel diminuição da anarmonicidade com o aba ixamento da temperatura ( $V$. o †tem seguinte) sugere que o 
efeito observado na intensidade da harmōnica esteja ligado com esta diminuição da anarmonicidade. Este relacionamento não é direto, pois a intensidade é ligada com a variaçãodo momento de dipolo induzido, enquanto que a anarmonicidade que medimos é mecânica.

3.5. Cálculo da anarmonicidade.

A observação de um grande nümero de harmōnicas no efeito Raman ressonante permite uma determinação precisa da constante de anarmonicidade $x_{11}$ e da frequéncia harmónica $\omega_{1}$.

Num oscilador anarmōnico a frequēncia $\left(e \mathrm{~cm}^{-1}\right.$ ) de uma vibração envolvendo o nūmero quântico vibracional vé dada por: $v_{v}=G(v)-G(0)=\omega_{1} v-x_{11}\left(v^{2}+v\right)+\ldots$, que pode ser re escrito:

$$
v_{v} / v=\left(\omega_{1}-x_{11}\right)-x_{11} v \quad(v=1,2, \ldots)
$$

Com os valores de $v_{v}$ observados em temperatura am biente e de $\mathrm{N}_{2}$ lĩquido obtivemos o grāfico da Figura 3.5 , de $v_{v} / v$ em função de $v$. O coeficiente angular da reta obti da dá o valor de $x_{1}$, que por substituição em (I) permite calcular o valor de $\omega_{1}$.

os valores obtidos foram:

Temperatura: $300 \mathrm{~K} \quad x_{11}=1,17 \mathrm{~cm}^{-1} ; \omega_{7}=393,6 \mathrm{~cm}^{-1}$ Temperatura: $100 \mathrm{~K} \quad x_{11}=0,49 \mathrm{~cm}^{-1} ; \omega_{1}=393,6 \mathrm{~cm}^{-1}$. 

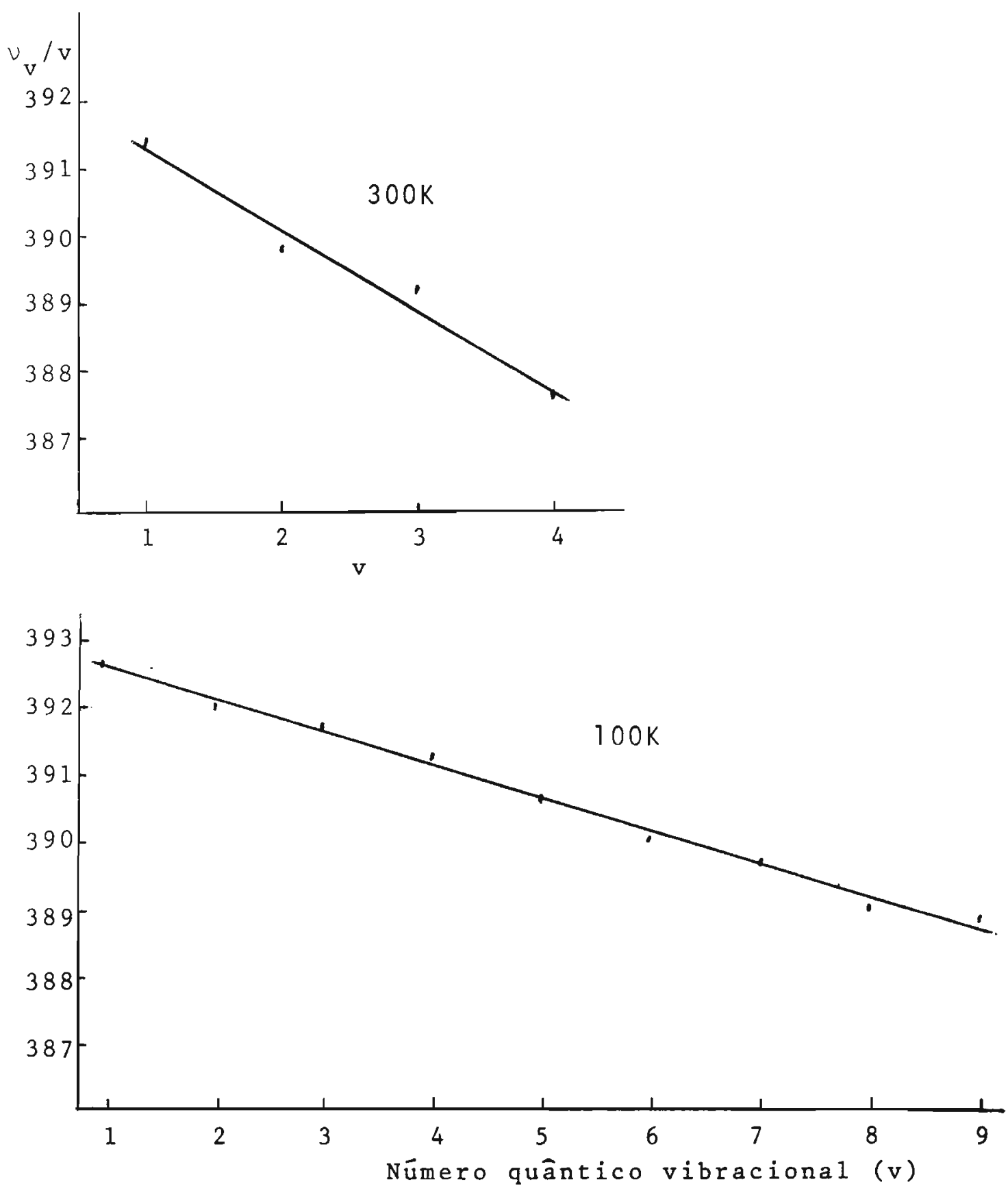

Figura 3.5. Determinação da constante de anarmonicidade $\mathrm{X}_{11}$ para $\mathrm{CCu}_{3} \mathrm{PS}_{4} \cdot\left(\mathrm{v}_{\mathrm{obs}} / \mathrm{v}\right.$ versus $\left.\mathrm{v}\right)$. 
36 Eferto Raman ressonante

No estudo do efeito Raman ressonante trabalhamos com medidas de intensidade das bandas. Como vimos no capI tulo 2, para que estas medidas caracterizem propriedades in trínsecas do composto investigado è necessārio que se remo va a dependēncia com fatores experimentais e instrumentais.

0 acoplamento ressonante entre a radiação excitante e os estados eletrónicos da molēcula é o fator decisivo na intensidade do espalhamento Raman ressonante. O aumento de intensidade em bandas Raman fundamentais e harmōnicas, devido a esse acoplamento, caracteriza o efeito Raman res sonante.

Na Figura 3.6 mostramos o espectro Raman ressonante do $\mathrm{Cu}_{3} \mathrm{PS}_{4}$ em baixa temperatura, excitado pela radiação $476,5 \mathrm{~nm}$. Podemos observar a presença de uma progressão de harmōnicas da $v_{1}=392 \mathrm{~cm}^{-1}$ e de combinações de outros modos vibracionais com esta progressão, como nos agrupamentos as sinalados por a, b, c.

Como a amostra está na forma de pó prensado pode mos esperar, devido a processos de absorção e reflexão da radiação incidente e da espalhada, que a intensidade Raman observada seja diminuida de um fator considerável, em com paração com amostras no estado líquido.

$\mathrm{Na}$ Figura 3.7 apresentamos os espectros Raman res sonante, obtidos com 3 radiações excitantes, da amostra em 


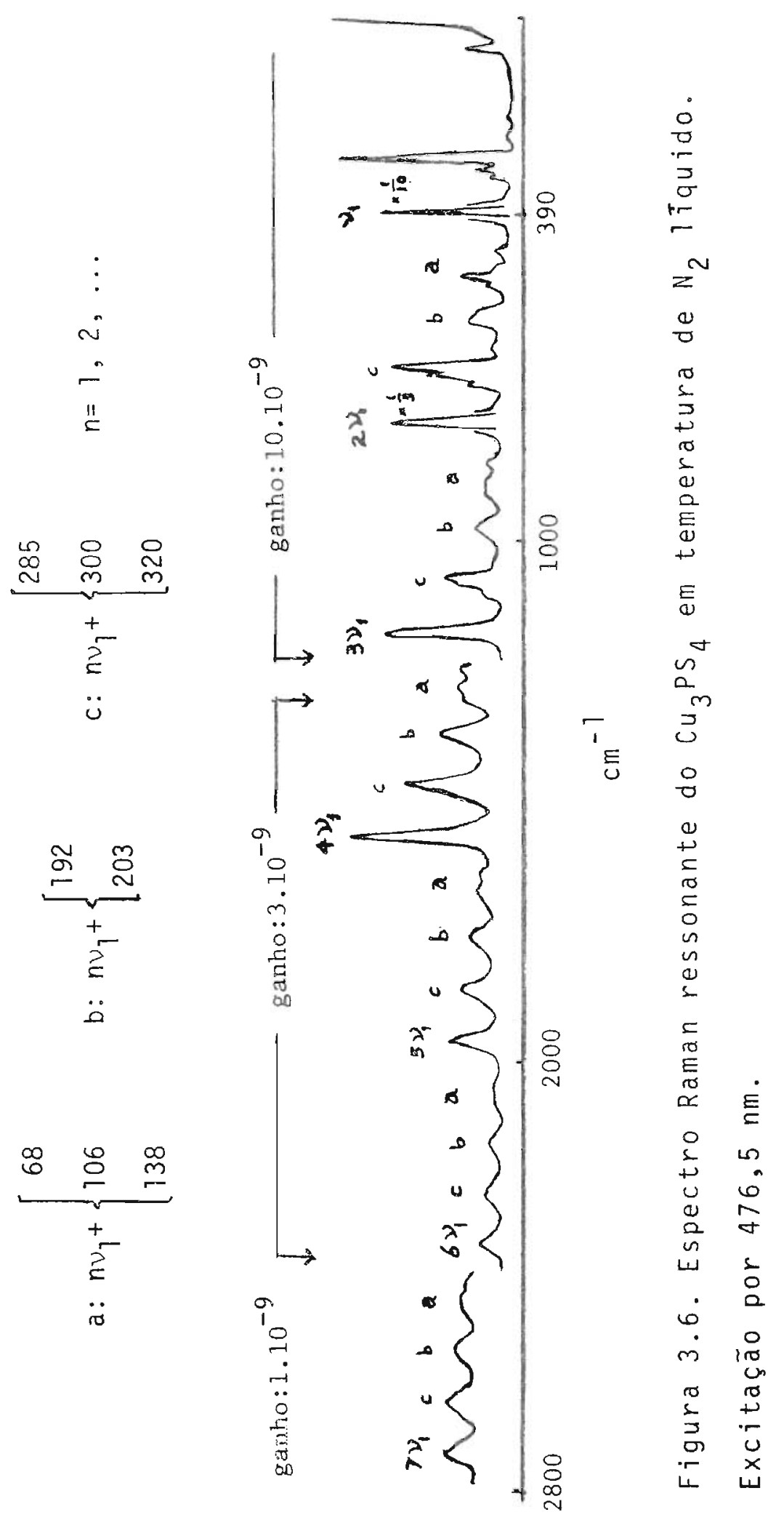




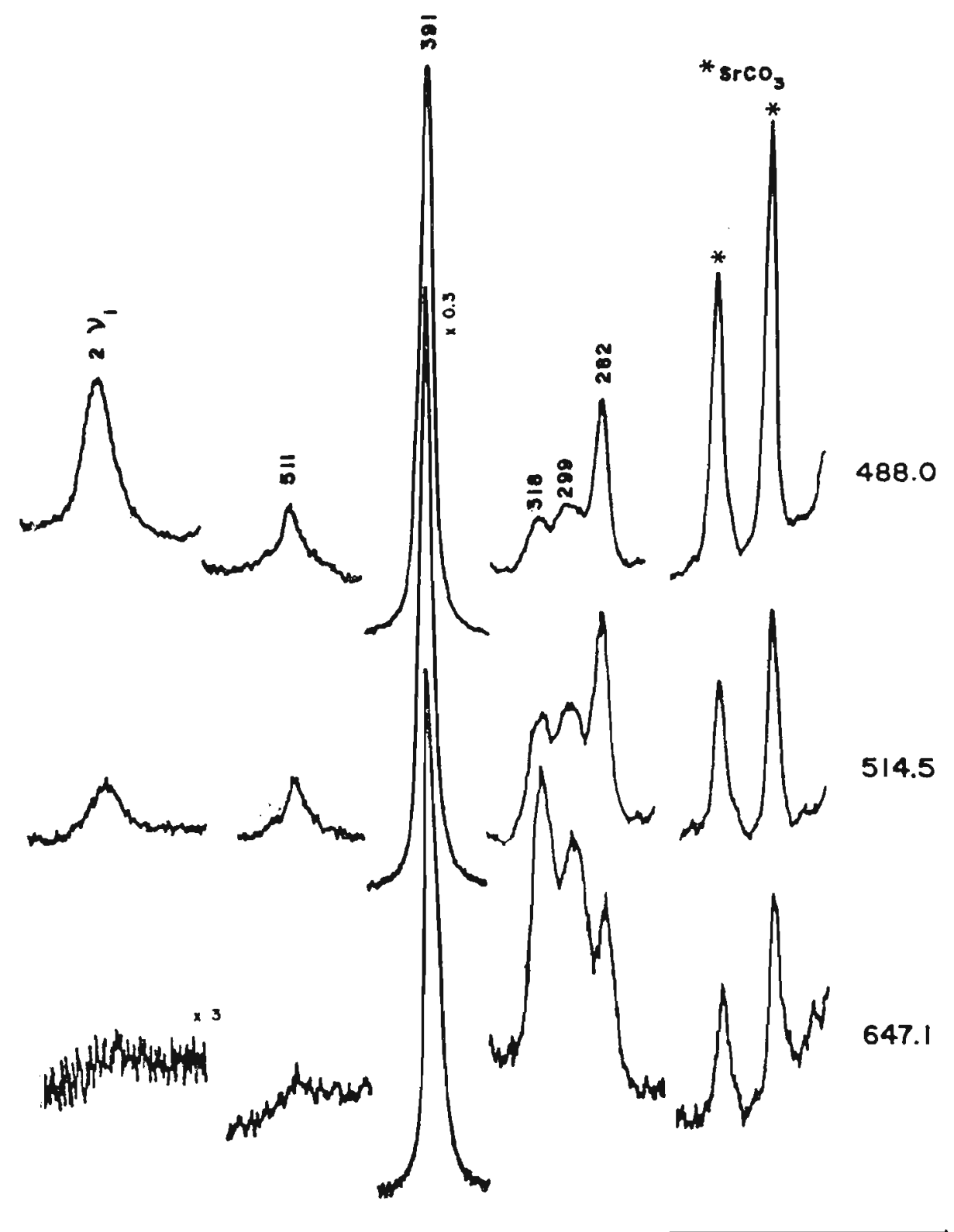

Figura 3.7. Variação.de intensidade no espectro do $\mathrm{Cu}_{3} \mathrm{PS}_{4}$ por efeito Raman ressonante. Estão indicados os comprimentos de onda $(\mathrm{nm})$ das radiações excitan tes. 
ela rotatōria dividida em setores com $\mathrm{Cu}_{3} \mathrm{PS}_{4}$ e com $\mathrm{SrCO}_{3}$. Nestes espectros a intensidade da banda $391 \mathrm{~cm}^{-1}$ foi manti da constante, e o aumento de intensidade das bandas do $\mathrm{SrCO}_{3}$, indo da radiação excitante 647,1 para $488,0 \mathrm{~nm}$, in dica na realidade uma diminuição na intensidade das bandas do $\mathrm{Cu}_{3} \mathrm{PS}_{4}$ devido à absorção.

Para obtermos a variação de intensidade somente de vida ao efeito Raman ressonante devemos, alēm das correçōes discutidas no capitulo 2, corrigir as intensidades observa das por um fator que cancele o efeito de absorção. Pelo fá to da amostra estar na forma de pó prensado não se pode di zer que este"fator de absorção" seja somente devido à absorção de luz pelo $\mathrm{Cu}_{3} \mathrm{PS}_{4}$, podendo haver contribuição de vido a processos de reflexão.

Desenvolvemos um método para determinar este fator de correção através dos espectros Raman. Obtivemos os es pectros, para sete radiações excitantes, de misturas homo

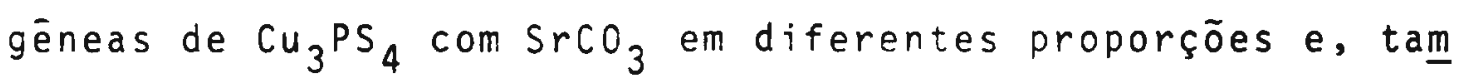
bém,os destes compostos separados em setores, na cela gira tōria.

Sendo Is a intensidade de uma banda do $\mathrm{SrCO}_{3}$ da $\underline{a}$ mostra em setores e $I_{h}$ a intensidade desta banda numa mi $\underline{s}$ tura homogēnea, construimos um gräfico de $\ln \left(I_{h} / I_{s}\right)$ versus - $(x+\ln x)$ para cada radiação excitante, sendo $x$ a fraçãomo lar de $\mathrm{Cu}_{3} \mathrm{PS}_{4}$ na mistura. Na construção destes gräficos ut lizamos valores de $x$ no intervalo de $1 / 10$ a $1 / 80$, sendo as 
curvas obtidas praticamente retas. Os valores extrapolados para $x=1$ fornecem a curva de correção desejada, quando co locados num gráfico em função do nūmero de onda absoluto das bandas correspondentes.

A correção assim obtida inclui reflexão e absorção da radiação incidente e reabsorção da radiação espalhada, ou seja, ela é uma correção efetiva do que é sentido pela amostra.

E interessante comparar a curva de correção, obtida pelo procedimento descrito, com as curvas de absorção no vi sível (pasta em Nujol) e de reflexão difusa, obtidas nos espectrofotometros Cary 17 e Zeiss PMQII, respectivamente. Estas curvas estão representadas na Figura 3.8, podendo-se notar que a curva de correção é mais semelhante à curva de reflexão do que à de absorção.

Para estudar a variação de intensidade devida ao $\underline{e}$ feito Raman ressonante, convēm eliminar da intensidade da radiação Raman espalhada a proporcionalidade com a quarta potência de sua frequência, dividindo o valor da intensida de experimental por esse fator de espalhamento.

os valores de intensidade dos modos internos e da primeira harmōnica da $392 \mathrm{~cm}^{-1}$, do $\mathrm{Cu}_{3} \mathrm{PS}_{4}$, são apresenta dos nas Tabelas 3 . III e 3.IV, para temperatura ambiente $e$ de nitrogênio 1 íquido, respectivamente. Os valores de inten sidade observados foram normalizados para o da linha 148 

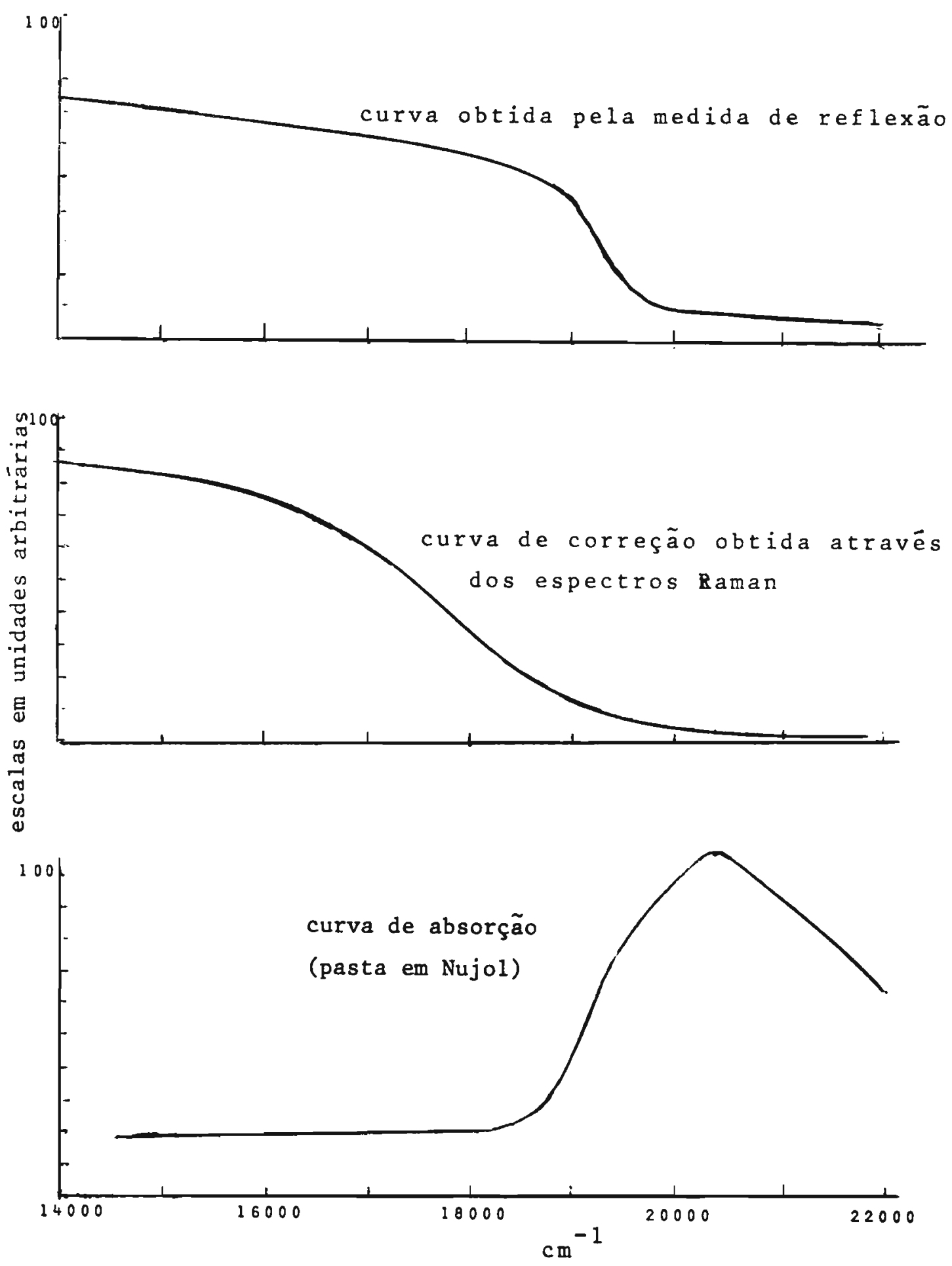

Figura 3.8. Comparação entre a curva de correção obtida atravēs do Raman e as de absorção e reflexão difusa. 
TABELA 3.III.

Valores de intensidade para $0 \mathrm{Cu}_{3} \mathrm{PS}_{4}$, em temperatura ambi ente.

$$
\text { I exp. normalizado para a banda } 148 \mathrm{~cm}^{-1} \text { do } \mathrm{SrCO}_{3}
$$

\begin{tabular}{|c|c|c|c|c|c|c|}
\hline \multirow{2}{*}{$\begin{array}{l}\lambda \text { exc. } \\
(\mathrm{nm})\end{array}$} & \multicolumn{6}{|c|}{ Frequências vibracionais $\left(\mathrm{cm}^{-1}\right)$} \\
\hline & 282 & 299 & 318 & 391 & 511 & 780 \\
\hline 647,1 & 117 & 157 & 197 & 1132 & 22 & 8,5 \\
\hline 568,2 & 163 & 171 & 213 & 1768 & 45 & 10 \\
\hline$5 \longdiv { 4 , 5 }$ & 370 & 217 & 209 & 3348 & 96 & 78 \\
\hline 496,5 & 533 & 220 & 173 & 5433 & 153 & 247 \\
\hline 488,0 & 431 & 162 & 137 & 4625 & 162 & 350 \\
\hline 476,5 & 182 & 104 & 114 & 3318 & 159 & 391 \\
\hline 457,9 & 102 & 76 & 82 & 1837 & 93 & 195 \\
\hline
\end{tabular}

Valores acima com as correções indicadas no texto:

$\begin{array}{rrrrrrr}647,1 & 127 & 173 & 222 & 1363 & 29 & 13 \\ 568,2 & 253 & 269 & 339 & 2800 & 72 & 18 \\ 514,5 & 3470 & 2078 & 2052 & 31935 & 787 & 457 \\ 496,5 & 13850 & 5775 & 4579 & 131600 & 3109 & 3576 \\ 488,0 & 12800 & 4857 & 4143 & 144029 & 4892 & 8540 \\ 476,5 & 5400 & 3114 & 3457 & 103343 & 5114 & 13629 \\ 457,9 & 3028 & 2288 & 2486 & 57200 & 2971 & 6800\end{array}$


TABELA 3 . IV.

Valores de intensidade para $0 \mathrm{Cu}_{3} \mathrm{PS}_{4}$, em temperatura de $\mathrm{N}_{2}$ î́quido.

I exp. normalizado para a banda $148 \mathrm{~cm}^{-1}$ do $\mathrm{SrCC}_{3}$

\begin{tabular}{|c|c|c|c|c|c|c|c|c|c|}
\hline \multirow{2}{*}{$\begin{array}{l}\text { exc. } \\
(\mathrm{nm})\end{array}$} & \multicolumn{9}{|c|}{ Frequēncias vibracionais $\left(\mathrm{cm}^{-1}\right)$} \\
\hline & 285 & 300 & 307 & 320 & 392 & 512 & 784 & 1175 & 1565 \\
\hline 647,1 & 30 & 26 & 33 & 42 & 211 & 4,5 & 1,5 & & \\
\hline 568,2 & 47 & 37 & 47 & 47 & 360 & 11 & 3,3 & & \\
\hline 514,5 & 125 & 30 & 80 & 68 & 784 & 34 & 18 & 2,4 & \\
\hline 496,5 & 290 & 67 & 116 & 90 & 1603 & 57 & 78 & 6.1 & 2 \\
\hline 488,0 & 393 & 44 & 118 & 60 & 2172 & 58 & 166 & 43 & 16 \\
\hline 476,5 & 207 & 18 & 45 & 30 & 1573 & 53 & 429 & 174 & 80 \\
\hline 457,9 & 14 & 6 & 5 & 5 & 126 & 7 & 37 & 40 & 36 \\
\hline
\end{tabular}

Valores acima com as correções indicadas no texto:

$\begin{array}{rrrrrrrrrr}647,1 & 33 & 28 & 36 & 47 & 254 & 6 & 3 & & \\ 568,2 & 73 & 58 & 74 & 75 & 569 & 17 & 6 & & \\ 514,5 & 1174 & 283 & 770 & 670 & 7477 & 280 & 100 & 10 & \\ 496,5 & 7550 & 1750 & 3050 & 2400 & 38822 & 1164 & 1000 & 70 & 15 \\ 488,0 & 11686 & 1314 & 3543 & 1800 & 67629 & 1770 & 4380 & 710 & 190 \\ 476,5 & 6143 & 543 & 1329 & 914 & 49000 & 1686 & 15930 & 6175 & 1680 \\ 457,9 & 414 & 180 & 151 & 151 & 3914 & 223 & 1360 & 1640 & 1600\end{array}$


$\mathrm{cm}^{-1}$ do $\mathrm{SrCO}_{3}$ e os valores corrigidos incluem todas as cor reçōes que discutimos.

3.6.1. Perfîl de excitação

Com os valores de intensidade jā corrigidos, apre sentados nas Tabelas 3.III e 3.IV, podemos levantar o per fỉ de excitação das bandas Raman.

Na literatura, geralmente este perfîl é obtido num gräfico de intensidade da banda em função do comprimentode onda ou do nümero de onda ${ }^{7,8}$. Achamos mais conveniente re presentar um perfil de excitação que mostre o efeito Raman ressonante independentemente da intensidade da banda.

Com este objetivo, representamos, em função do nūme ro de onda da radiação excitante, a relação de intensidade de uma banda Raman obtida por essa excitação com a intensi dade desta banda obtida por excitação de uma radiação lon ge da região de absorção eletrōnica, que portanto não apre senta efeito Raman ressonante. Para $\mathrm{C}_{\mathrm{Cu}_{3} \mathrm{PS}_{4}}$ a radiação do laser de $\mathrm{Kr}^{+}, 647,1 \mathrm{~nm}$, è sufientemente afastada da banda de absorção e as intensidades das bandas Raman por ela ex citadas podem ser tomadas como referencia.

Na Figura 3.9 representamos os perfís de excitação obtidos em temperatura ambiente e de nitrogênio liqquido. observa-se que a banda em $512 \mathrm{~cm}^{-1}$ apresenta um perfíl se melhante ao da banda em $392 \mathrm{~cm}^{-1}$, embora elas sejam, respec 


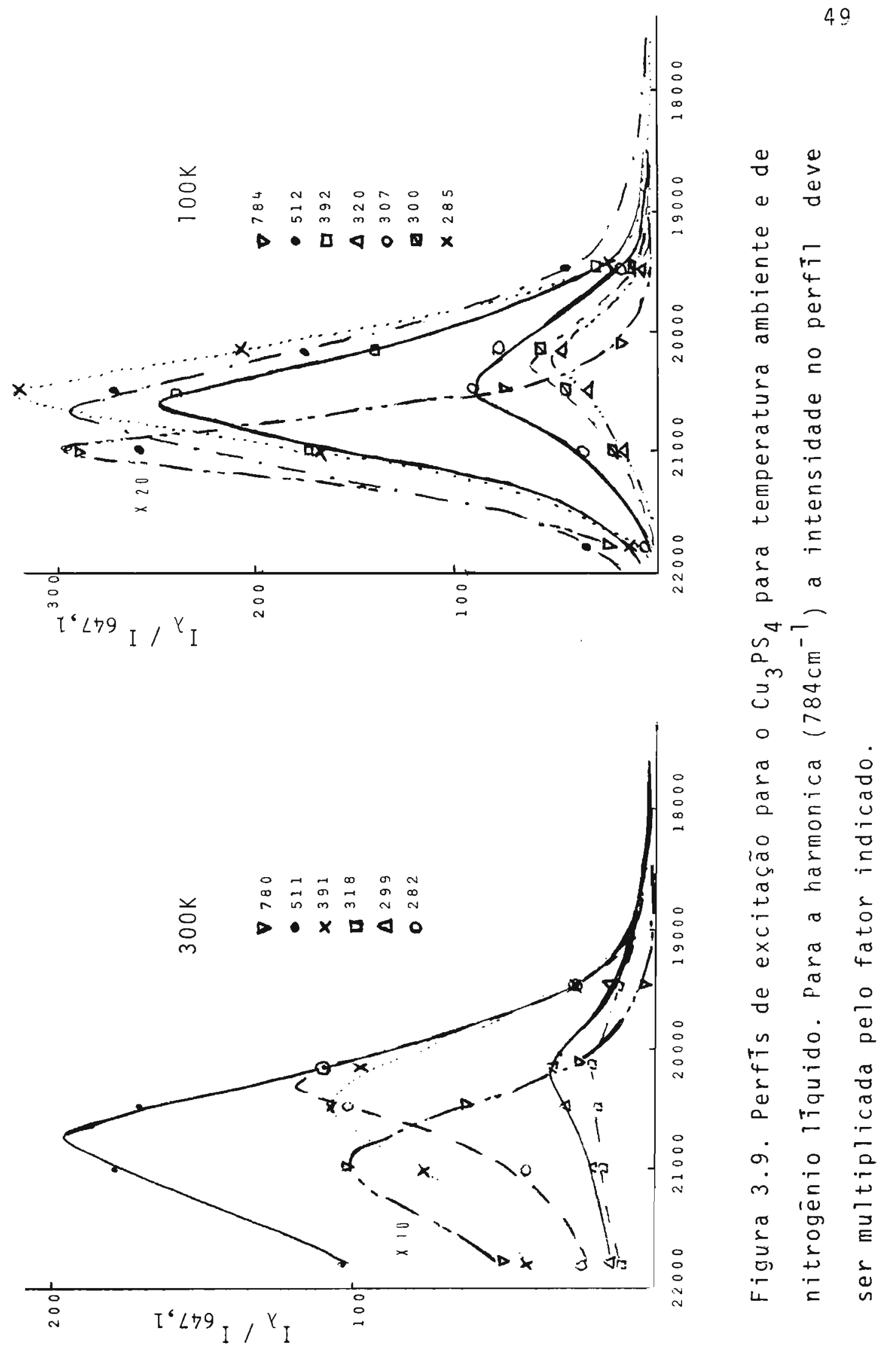


tivamente a menos intensa e a mais intensa dos modos inter nos. A harmōnica, praticamente não observada no espectro Raman ordinārio, apresenta o maior perfīl, em nossa representação.

Em trabalho anterior ${ }^{9}$ apresentamos o perfil de ex citação do $\mathrm{Cu}_{3} \mathrm{PS}_{4}$ em temperatura ambiente e apontamos o fa to de que o pico do perfíl para a harmōnica se apresentava deslocado para o lado de menores comprimentos de onda, em relação ao pico da fundamental. Entretanto, um estudo mais preciso destes perfis seria melhor conduzido obtendo-se os espectros em baixa temperatura, onde as bandas se apresentam melhor resolvidas. Assim, iremos discutir somente os perfís obtidos dos espectros em baixa temperatura.

observando os perfís de excitação, para temperatura de $\mathrm{N}_{2}$ līquido, vemos que as bandasem 285,392 e $512 \mathrm{~cm}^{-1}$ apresentam a mesma altura de perfîl. Como sabemos que a $392 \mathrm{~cm}^{-1}$ pertence a espēcie de simetria $\left(A_{1}+B_{2}\right)$ podemos $\underline{u}$ sar este resultado para justificar a atribuição feita no tem 3.3 , da 285 e $512 \mathrm{~cm}^{-1}$ para a espécie $\left(A_{1}+B_{2}\right)$.

Poucos são os autores que se referem ao deslocamen to do pico dos perfís de excitação com o valor da frequēncia vibracional, podendo-se citar os trabalhos de spiro e col. 10 e de Kamisuki e col. 11 . Nos perfís da Figura 3.9 po de-se observar o deslocamento dos picos para o lado de ma ior nümero de onda, para frequências vibracionais mais al tas. 
Considerando o denominador da expressão para a in tensidade de uma banda Raman, obtida por Nafie e col. ${ }^{12}$, po demos escrever para as 1 inhas stokes, considerando os valo res experimentais de intensidade com as correções menciona das anteriormente jā efetuadas:

$$
I_{n} \propto \prod_{m=0}^{n}\left[\left(v_{e}-v+m v_{R}\right)^{2}+\Gamma^{2}\right]^{-1}=Q_{0} Q_{1} Q_{2} \ldots Q_{n}
$$

onde $\nu \bar{e}$ a frequēncia da radiação excitante $\left(\mathrm{cm}^{-1}\right), \nu_{R} \bar{e}$ a a frequēncia vibracional $\operatorname{Raman}\left(\mathrm{cm}^{-1}\right), r_{\bar{e}}$ o nūmero quânti covibracional, Г e o termo de amortecimento e v a frequēn cia eletrōnica efetiva. Com respeito à definição desta fre quência eletrōnica efetiva, chao e col. ${ }^{8}$ a identificam com o máximo no perfîl de excitação e Behringer ${ }^{\mathfrak{z}}$ a considera como o valor de $v_{e}$ que ajusta o valor teórico com o experi menta 1 .

Determinamos o valor de $v_{e}$ e $\Gamma$ ajustando-os para haver a melhor concordāncia do perfíl teörico, dado pelo segundo membro da equação acima, com os pontos experimenta is. Escrevendo explicitamente os termos da produtōria da expressão acima temos:

$$
\left[\left(v_{e}-v\right)^{2}+\Gamma^{2}\right]^{-1}\left[\left(\nu_{e}-v+v_{R}\right)^{2}+\Gamma^{2}\right]^{-1}\left[\left(v_{e}-v+2 v_{R}\right)^{2}+\Gamma^{2}\right]^{-1} \ldots .
$$

Supondo inicialmente $v_{e}>v$ e que vamos aumentando a frequén cia de excitação v, o lọ termo entrará em ressonāncia quan do $v_{e}=\nu$, mas como 020 termo não entrou em ressonāncia a banda Raman não atinge o máximo de intensidade. Quando o 
20 termo entra em ressonancia, isto $\bar{e}, \nu_{e}=\nu-v_{R}, 010$ termo jä sai de ressonāncia. A posição de māximo do produto des tes dois termos não serā nem em $v$ nem em $v-v_{R}$, mas num va lor intermediārio. Quanto maior for $v_{R}$ maior deverá ser $v$ para este máximo. Para a primeira harmōnica o 30 termo en tra em ressonāncia para $\nu_{e}=\nu-2 v_{R}$ e pela contribuição deste termo o mäximo ocorrerā numa frequēncia excitante maior do que a do māximo para a fundamental.

Para as frequēncias fundamentais 285,392 e $512 \mathrm{~cm}^{-1}$ os valores de $v_{e}$ e $v$ que deram melhor concordáncia dos pon tos experimentais com o perfîl teórico lobtido com estes pa râmetros) foram $\nu_{e}=20400 \mathrm{~cm}^{-1}$ e $\Gamma=700 \mathrm{~cm}^{-1}$, enquanto que pa ra as harmōnicas $2 v_{1}, 3 v_{1}$ e $4 v_{1}\left(v_{1}=392 \mathrm{~cm}^{-1}\right)$ foram $v_{e}=20600 \mathrm{~cm}^{-1}$ e $\Gamma=500 \mathrm{~cm}^{-1}$. Como a diferença entre os valores de $v_{\text {e }}$ estão dentro do erro experimental, fizemos um cālculo com o valor médio de $v_{e}, 20500 \mathrm{~cm}^{-1}$, mantendo os valores de $\Gamma$.

$\mathrm{Na}$ Figura 3.10 estão representados os perfís teōri cos calculados com $\nu_{e}=20500 \mathrm{~cm}^{-1}$ e $\Gamma=700 \mathrm{~cm}^{-1}$, em $A$, e com $v_{e}=20400 \mathrm{~cm}^{-1}$ e $\Gamma=700 \mathrm{~cm}^{-1}$, em B. Os valores teōricos e expe rimentais foram normalizados para valor 100 no pico. Na Fi gura 3.11 estão representados os perfis teóricos para as harmōnicas $2 v_{1}, 3 v_{1}$ e $4 v_{1}$ e 0 de $v_{1}$ como comparação, sendo em $A: v_{e}=20500 \mathrm{~cm}^{-1}$ e $\Gamma=500 \mathrm{~cm}^{-1}$ e em $B: \nu_{e}=20600 \mathrm{~cm}^{-1}$ e $\Gamma=$ $500 \mathrm{~cm}^{-1}$.

Os espectros de absorção no visîvel, usando pasta em Nujol, não foram de boa qualidade, não havendo reprodu 


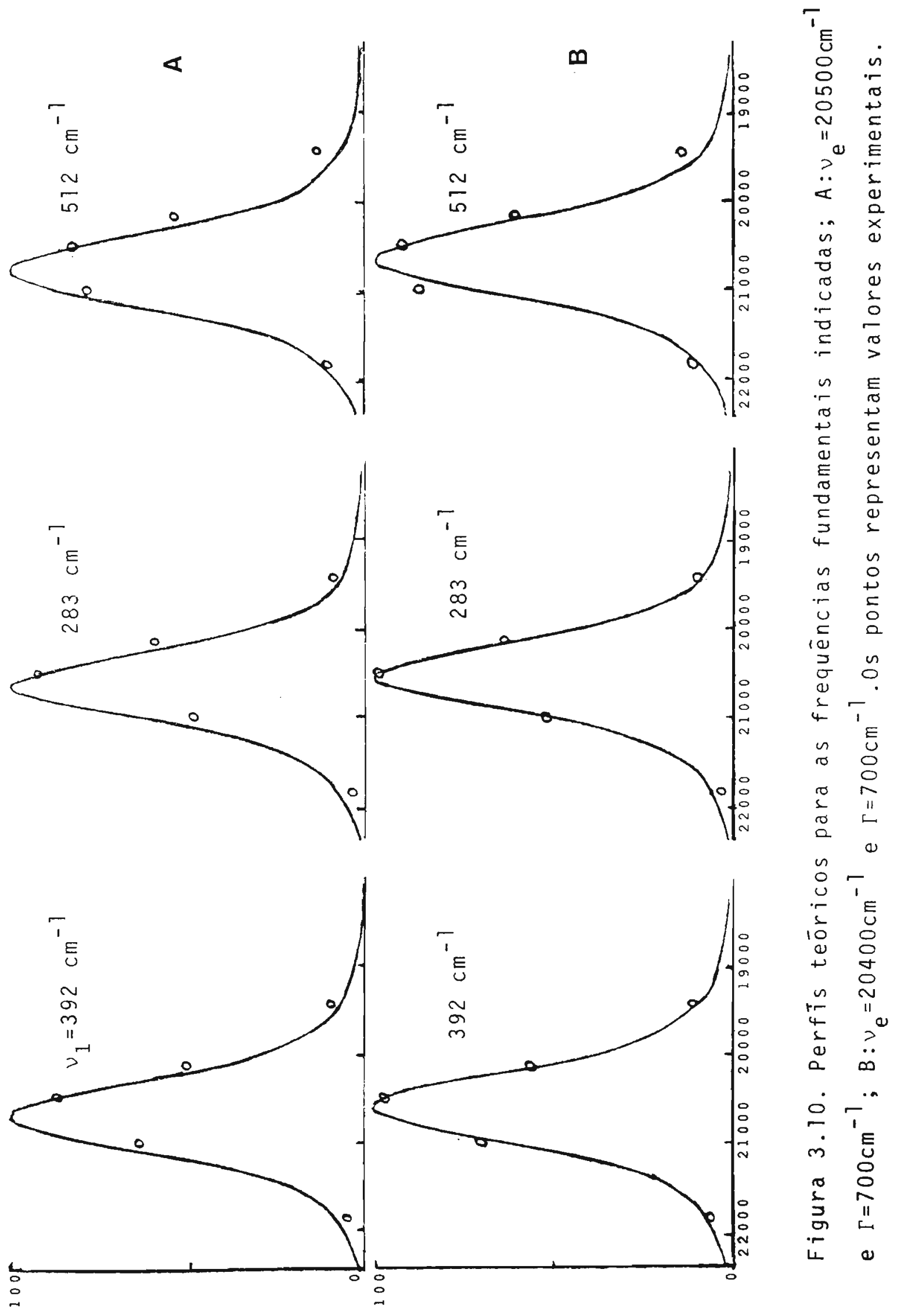



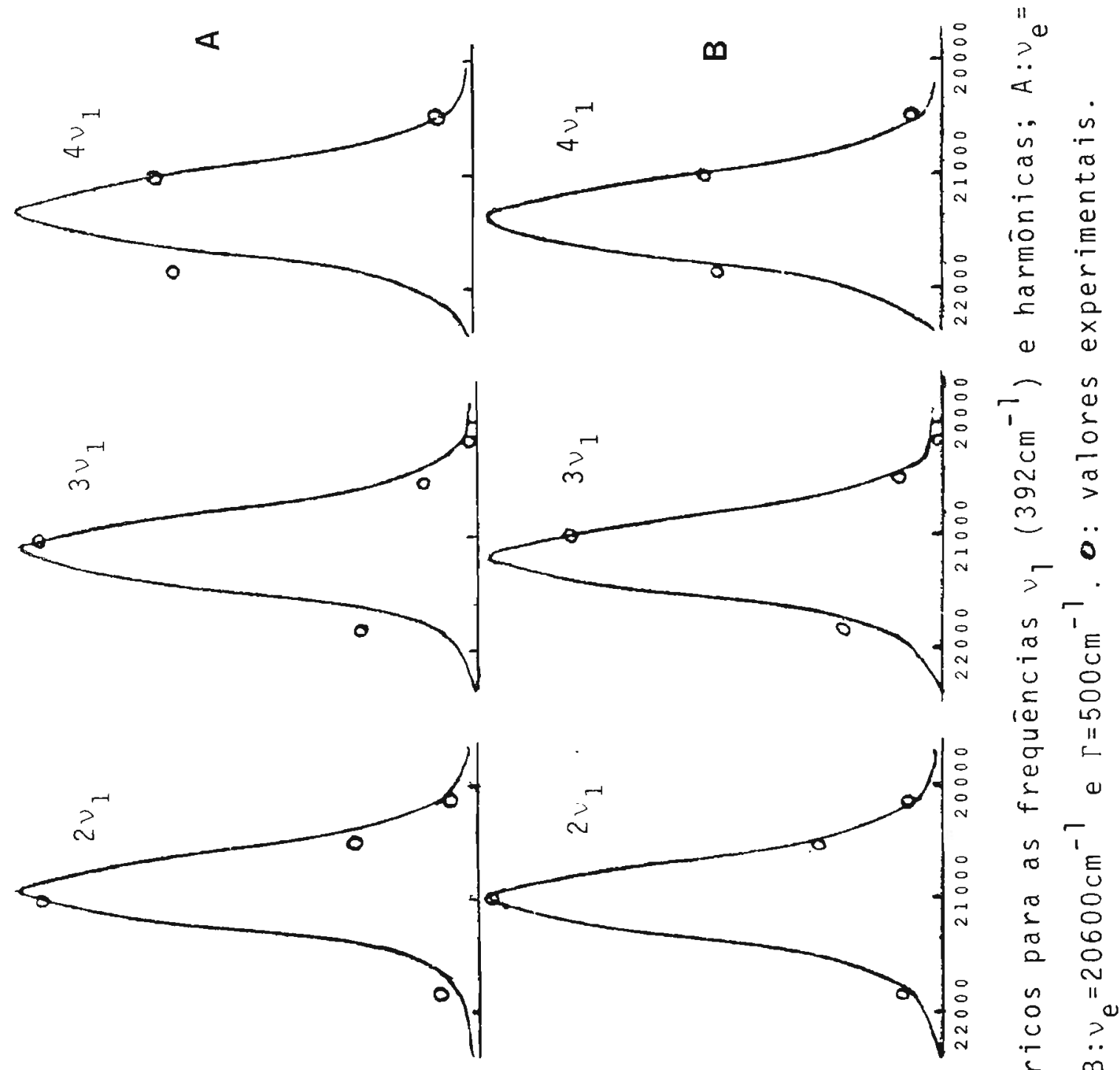

$10 \quad \frac{a}{0}$

TE

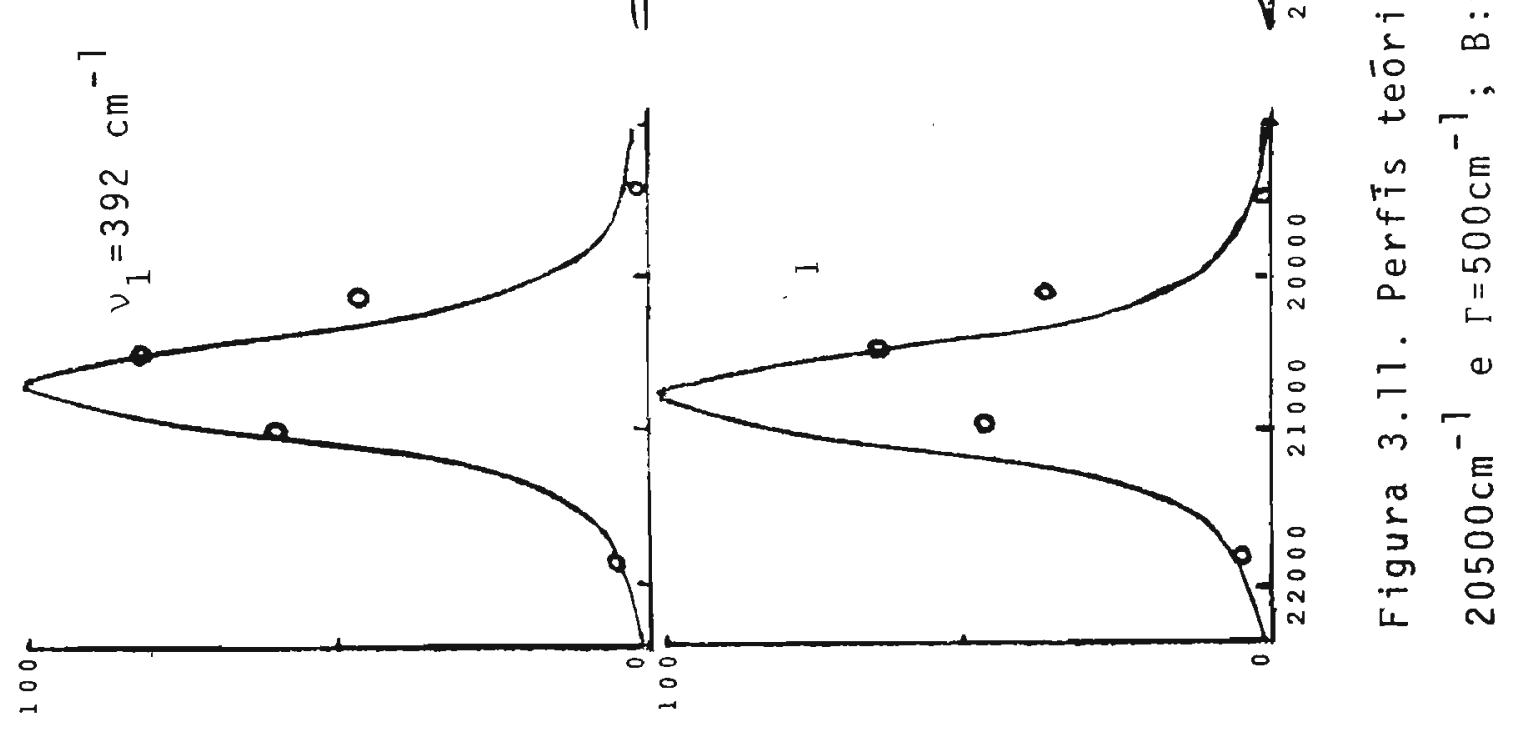


tibilidade dos espectros com diferentes pastas, havendo mu dança da posição do pico. Isto impede que se possa discu tir o valor de ve em relação ao valor do māximo de absor ção.

A intensa absorção no visível indica que o valor de $\varepsilon$ do $\mathrm{Cu}_{3} \mathrm{PS}_{4}$ deve ser elevado, característico de bandas de transferência de carga. Isto é reforçado pelo fato do $\mathrm{Na}_{3} \mathrm{PS}_{4}$ ser incolor, indicando que as bandas eletrónicas do agrupamento $\mathrm{PS}_{4}^{3-}$ estão situadas na região do ultravioleta. os resultados que obtivemos neste estudo mostram que não é correta a afirmação feita em vários trabalhos so bre Raman ressonante 14,15 de que a intensidade das harmōni cas decresce monotonicamente com o número quāntico vibracio nal. Essa afirmação sō è vālida quando a frequēncia espaThada das harmónicas for menor do que $v_{e}$. Na Figura 3.12 representamos a intensidade das harmônicas em relaçãoà in tensidade da fundamental ( I nvil I ) para värias radiações excitantes em função da frequễncìa Raman espalnada. Obser va-se para excitação com $457,9 \mathrm{~nm}$ que a intensidade rela tiva da terceira e quarta harmōnica são praticamente i guais e maior do que a da primeira harmōnica. Para as de mais radiações jā a condição $\nu_{n v}<\nu_{e} \bar{e}$ satisfeita e a in tensidade das harmōnicas decai continuamente. 


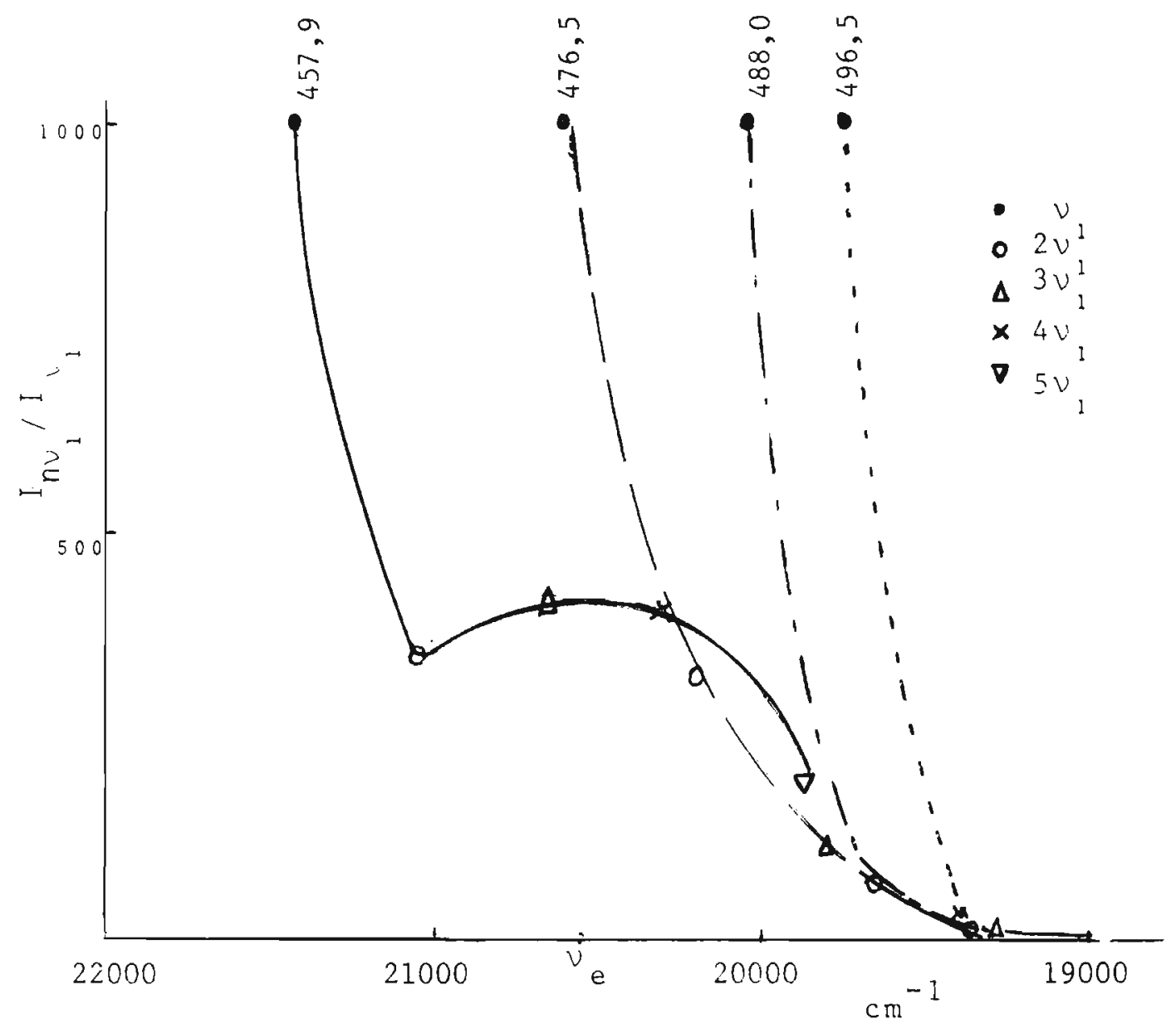

Figura 3.12. Variação da relação das intensidades das harmōnicas em relação à intensidade da fundamental com a frequência espalhada. Em cada curva esta indicada a radiação excitante utilizada. 


\section{REFERENCIAS}

1 Leroy,J.F., Kaufmann,G., Muller,A. e Roesky,H.W.: Compt.Rend.Acad.Sci.(Paris), 267, 563 (1968).

2 Mellor,J.W.: A comprehensive treatise on inorganic and theoretical chemistry, Vol.8. Longmans, London (1953).

3 Kiefer,W. e Bernstein,H.J.: Appl. Spectry., 25, 609 (1971).

4 Ferrari,A. e Cavalca,L.: Gazz.Chim.Ital., 78, 283 (1948).

5 Nitshe,R. e Wild,P.: Mat.Res.Buzl.,5, 419 (1970).

6 Fateley,W.G. e Dollish,F.R.: Infrared and Raman Selection Rules for Molecular and Lattice Vibrations: The Correlation Method. Carnegie-Mel1on University (1971).

7 Verma,A.L., Mendelsohn,R. e Bernstein,H.J.: J.Chem.Phys. $61,383(1974)$.

8 Chao,R.S., Khanna,R.K. e Lippincott,E.R.: J. Raman Spectrosc., 3, 121 (1975).

9 Sala,0. e Temperini,M.L.A.: Chem.Phys.Letters, 36, 652 $(1975)$.

10 Spiro,T.G., e Strekas,T.C.: Proc.Nat.Acad.Sci.USA, 69, $2622(1972)$.

11 Kamisuki,T.,Maeda,S. e Kobayashi,H.: J.Raman Spectrose.: $5,135(1976)$.

12 Nafie,L.A., Stein,P. e Peticolas,W.L.: Chem.Phys.Letters, $12,131(1971)$. 
13 Behringer,J.: Raman Spectroscopy (Szymanski,H.A. ed.) Vol.2-Cap.6. Plenum Press. N.Y. (1967).

14 Holzer,W., Murphy,W.F. e Bernstein,H.J.: J.Chem.Phys. $52,399(1970)$.

15 Clark,R.J.H. e Mitche11,P.D.: J.Amer.Chem.Soc. 95, $8300(1973)$. 


\section{CAPITULO 4}

$\mathrm{Ag}_{3} \mathrm{PS}_{4}$ : Espectro vibracional e atribuição das frequências. Espectro Raman ressonante.

4.1. Introdução

Para o tiofosfato de prata não hā na literatura indicações sobre o grupo espacial. Ferrari e Cavalca ${ }^{1}$ citam que o difratograma do $\mathrm{Ag}_{3} \mathrm{PS}_{4} \overline{\mathrm{e}}$ completamente diferente do $\mathrm{Cu}_{3} \mathrm{PS}_{4}$.

0 mētodo de preparação, de obtenção dos espectros e correções de intensidade é o mesmo utilizado para o $\mathrm{Cu}_{3} \mathrm{PS}_{4}$ e não será descrito novamente. O produto de parti da na preparação foi o $\mathrm{AgCl}$.

Para $\mathrm{Ag}_{3} \mathrm{PS}_{4}$ não obtivemos pico de absorção no visivel, empregando a mesma técnica utilizada para o $\mathrm{Cu}_{3} \mathrm{PS}_{4}$. 0 espectro de reflexão difusa mostrou um desloca mento, em relação ao do $\mathrm{Cu}_{3} \mathrm{PS}_{4}$, para o lado de menor com primento de onda.

Os espectros Raman indicam que a região investigada é de pre-ressonāncia, não havendo pico no perfĩl de excitação.

4.2. Atribuição das frequẽncias

Os espectros Raman do $\mathrm{Ag}_{3} \mathrm{PS}_{4}$ em temperatura ambi 
ente e de nitrogēnio líquido são mostrados na Figura 4.1. Na Tabela 4 .I estão os valores das frequências observadas, Raman e infravermelho. Como não conhecemos o grupo de fa tor a atribuição foi feita com a aproximação do agrupamen to $\mathrm{PS}_{4}{ }^{3-}$ à simetria $T_{d}$, com desdobramento das frequências degeneradas por efeito de campo estātico e por analogia com - $\mathrm{Cu}_{3} \mathrm{PS}_{4}$. Na aproximação de simetria $\mathrm{T}_{d}$ as bandas com coin cidência no Raman e infravermelho são de espécie $F_{2}$, sendo os modos de espēcie $A_{1}$ e E ativos só no Raman. Não observa mos o desdobramento da banda de espécie E, mesmo em baixa temperatura.

Nota-se para $\mathrm{Ag}_{3} \mathrm{PS}_{4}$ que as frequencias vibracionais são praticamente iguais as observadas para $0 \mathrm{Na}_{3} \mathrm{PS}_{4}{ }^{2}$. Comparando com o $\mathrm{Cu}_{3} \mathrm{PS}_{4}$ observa-se em relação à esse que as frequencias de estiramento $P-S$ são mais altas, enquanto que as frequências de deformação de āngulo são mais baixas.

\subsection{Efeito Raman ressonante}

Na Figura 4.2 são mostrados os espectros Raman pa ra diferentes excitações, não se observando neles uma va riação tão marcante como se observava para $0 \mathrm{Cu}_{3} \mathrm{PS}_{4}$.

Na Figura 4.3 comparamos o espectro de reflexão com a curva de correção obtida da relação $I_{h} / I_{s}$, com o mesmo procedimento descrito no capitulo 3.

Na Tabela 4.II estão os valores de intensidade ob servados e corrigidos, para temperatura de $\mathrm{N}_{2} 1 \mathrm{iquido.}$ 


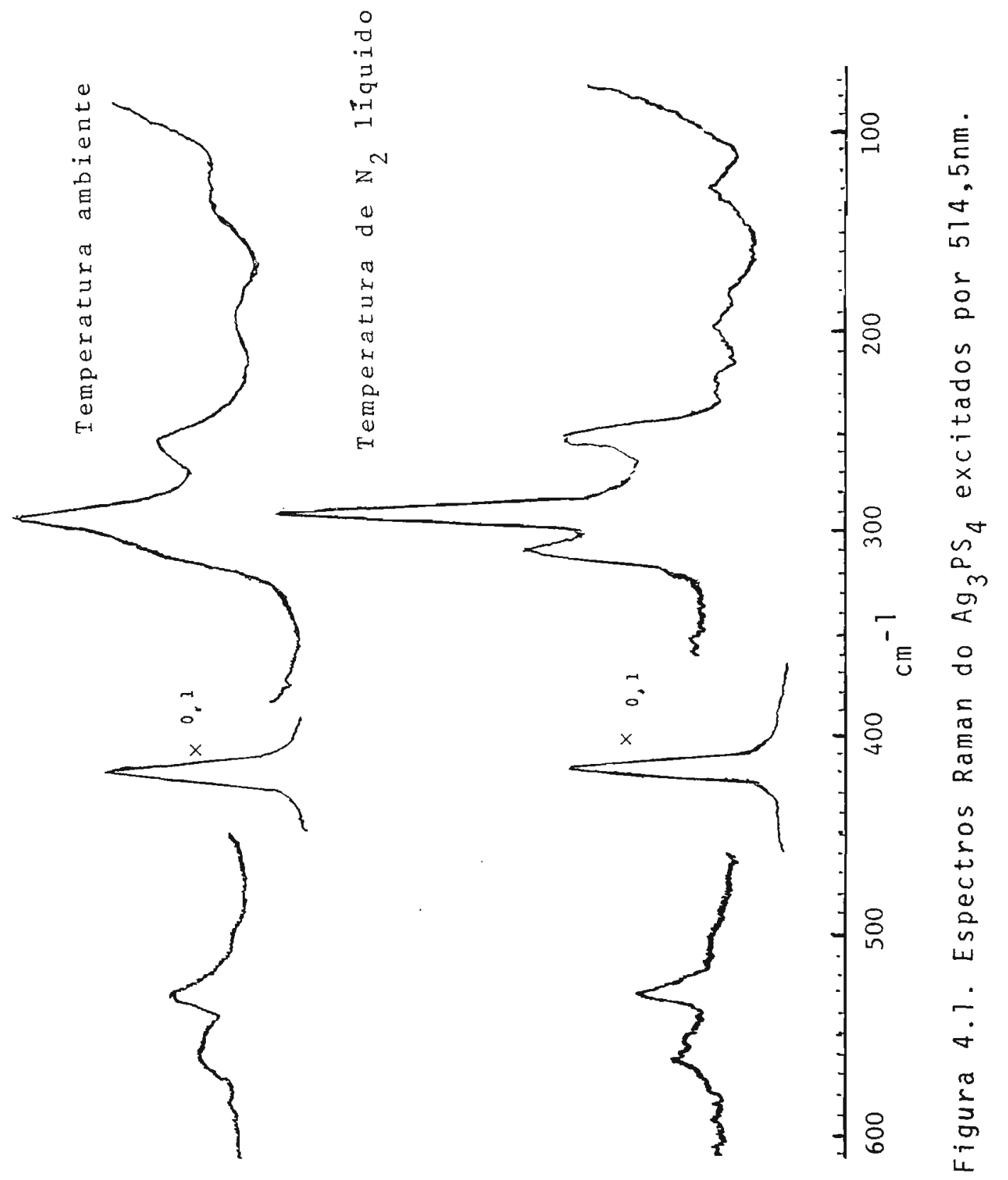


TABELA 4.I.

Valores das frequências $\left(\mathrm{cm}^{-1}\right)$ observadas nos espectros Raman e infravermelho do $\mathrm{Ag}_{3} \mathrm{PS}_{4}$.

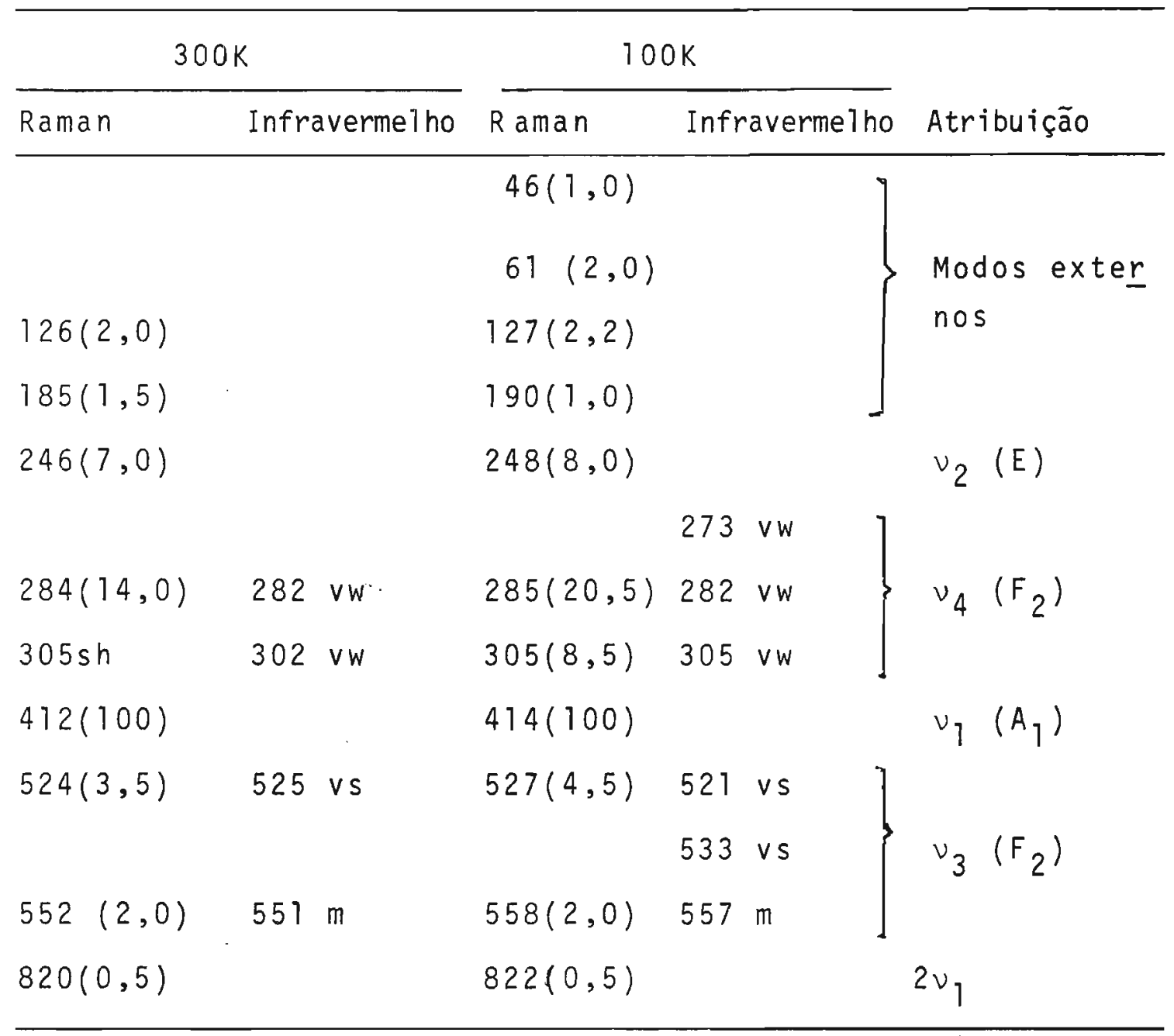

Intensidades referentes ao espectro excitado com $514,5 \mathrm{~nm}$. 

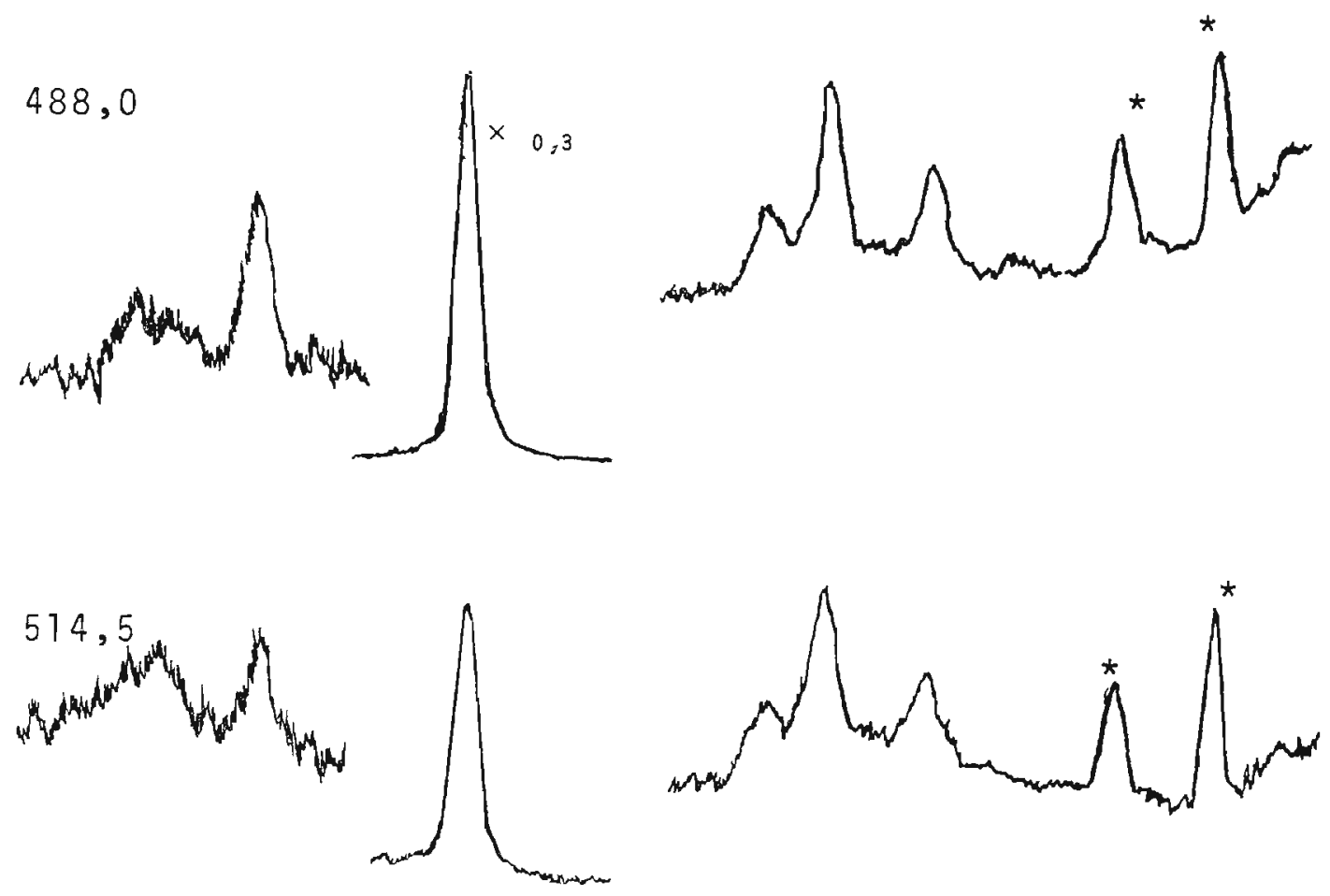

647,9
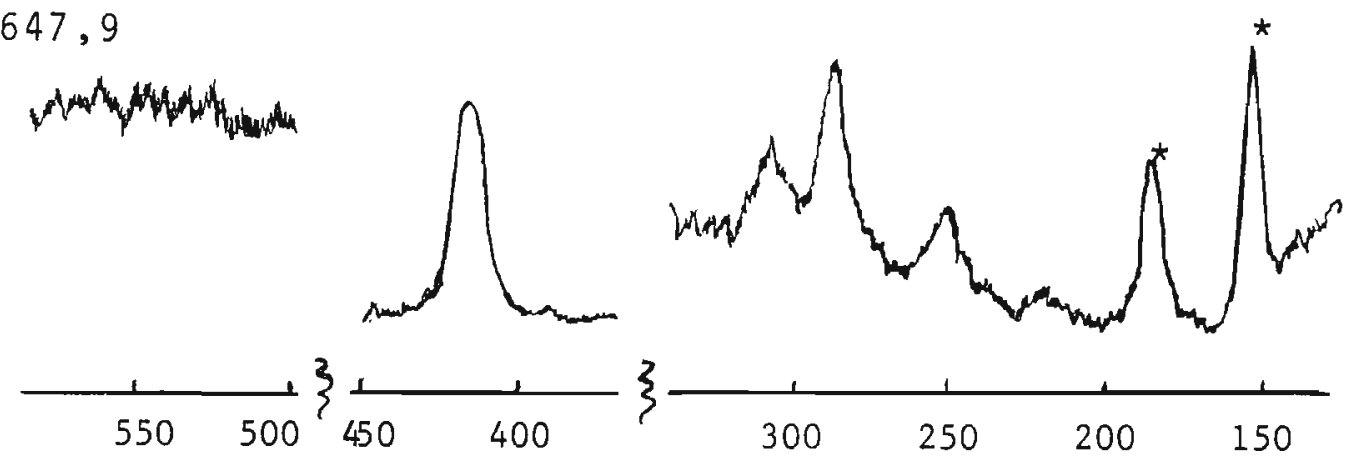

Figura 4.2. Espectros Raman do $\mathrm{Ag}_{3} \mathrm{PS}_{4}$ para diferentes radiaçōes excitantes, obtidos de uma mistura homogēnea com $\operatorname{SrCO}_{3}\left({ }^{*}\right)$. A esquerda estão indicados os comprimen tos de onda da linha excitante ( $n m)$. 

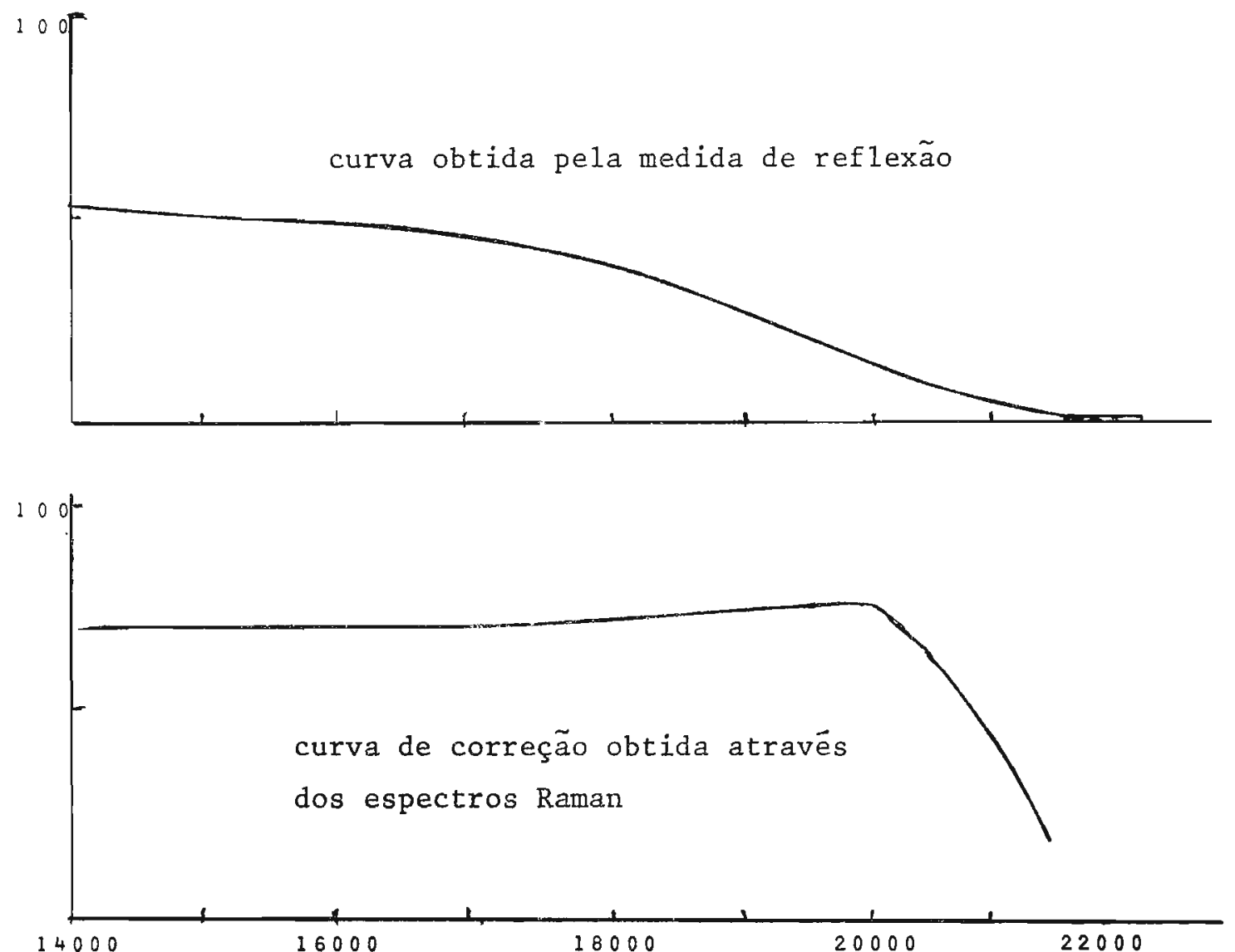

Figura 4.3. Comparação entre a curva de correção obtida atravēs do espectro Raman e a de reflexão difusa. 
TABELA 4.II.

Valores de intensidade para $\mathrm{O} \mathrm{Ag}_{3} \mathrm{PS}_{4}$, em temperatura amb 1 ente.

$$
\text { I exp. normalizado para a banda } 148 \mathrm{~cm}^{-1} \text { do } \mathrm{SrCO}_{3}
$$

\begin{tabular}{|c|c|c|c|c|c|c|c|}
\hline \multirow{2}{*}{$\begin{array}{l}\lambda_{\text {exc }} \\
(n m)\end{array}$} & \multicolumn{7}{|c|}{ Frequências vibracionais $\left(\mathrm{cm}^{-1}\right)$} \\
\hline & 248 & 285 & 305 & 414 & 527 & 558 & 822 \\
\hline 647,1 & 36 & 76 & 39 & 266 & & & \\
\hline 568,2 & 40 & 94 & 36 & 336 & 12 & 11 & \\
\hline 514,5 & 64 & 110 & 46 & 456 & 22 & 15 & 2 \\
\hline 496,5 & 70 & 122 & 45 & 672 & 35 & 12 & 4 \\
\hline 488,0 & 67 & 1.74 & 49 & 707 & 33 & 14 & 3 \\
\hline 476,5 & 78 & 143 & 61 & 1050 & 52 & 22 & 6 \\
\hline 457,9 & 60 & 70 & 27 & 710 & 40 & 13 & \\
\hline
\end{tabular}

Valores acima com as correções indicadas no texto:

$\begin{array}{rrrrrrrr}647,1 & 42 & 92 & 47 & 358 & & & \\ 568,2 & 46 & 110 & 46 & 423 & 21 & 15 & \\ 514,5 & 68 & 120 & 50 & 582 & 28 & 19 & 2 \\ 496,5 & 72 & 132 & 47 & 732 & 39 & 13 & 5 \\ 488,0 & 74 & 126 & 53 & 798 & 37 & 15 & 4 \\ 476,5 & 114 & 213 & 90 & 1357 & 70 & 30 & 8 \\ 457,9 & 221 & 264 & 100 & 2315 & 115 & 32 & \end{array}$


Devido a sobreposição das bandas em temperatura am biente consideramos o perfîl de excitação somente em baixa temperatura. Na Figura 4.4 o perfî de excitação mostra um aumento de intensidade das bandas em direção a frequēncias excitantes mais altas mas não hā o aparecimento de um māxị mo, como observado no $\mathrm{Cu}_{3} \mathrm{PS}_{4}$. Isto significa que $0 \mathrm{Ag}_{3} \mathrm{PS}_{4}$ apresenta somente prē-ressonãncia no intervalo que pudemos investigar.

Observando a tabela 4 .I I vemos que nos valores de intensidade normalizados hā um māximo em aproximadamente $476,5 \mathrm{~nm}$ e que apōs as correçōes de intensidade este māximo desaparece. Este comportamento é coerente com o fato de não termos observado um pico de absorção no visivel.

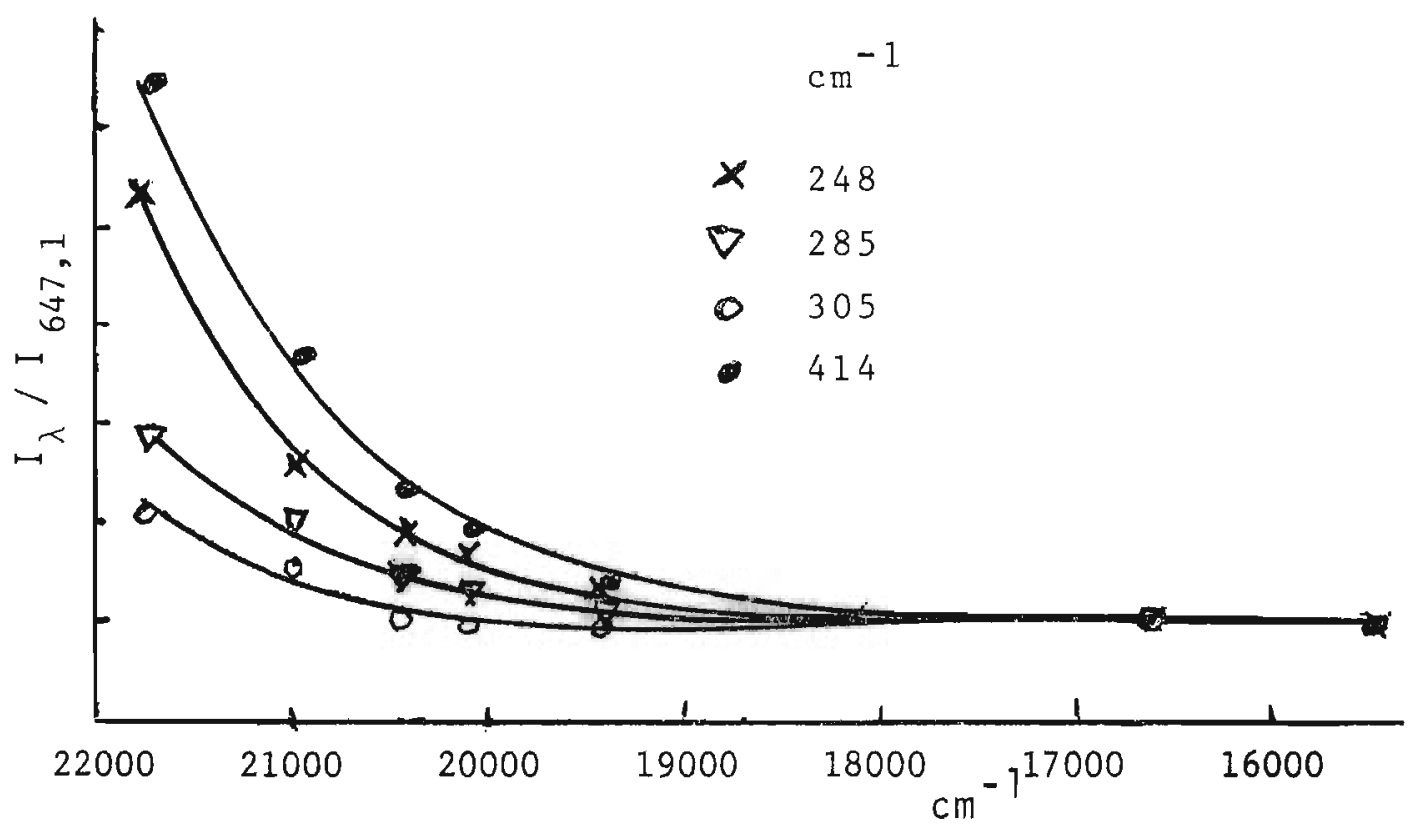

Figura 4.4. Perfĩl de excitação para $0 \mathrm{Ag}_{3} \mathrm{PS}_{4}$ 


\section{REFERENCIAS}

1 Ferrari,A. e CavalCa,L.: Gazz.Chim.Ital.,78, 283 (1948).

2 Leroy,J.F., Kaufmann,G, Muller,A. e Roesky,H.W.:

Compt.Rend.Acad.Sci.(Paris), 267, 563 (1968). 


\section{CAPITULO 5}

Dependência da intensidade Raman com a frequência espalhada. Estudo do modo vibracional totalmente simétrico do $\left(\operatorname{Mos}_{4}\right)^{2-}$.

\subsection{Introdução}

0 espectro Raman ressonante do ion $\left(\operatorname{Mos}_{4}\right)^{2-}$ foi es tudado por Ranade e Stockburger ${ }^{1}$, que obtiveram o perfTl de excitação e a secção de choque para a radiação total espa Ihada.

Observando-se a Figura 5.1, onde é representada a curva de absorção no visível do $\left(\operatorname{Mos}_{4}\right)^{2-} \operatorname{com}$ os valores das frequências de excitação e espalhadas (Stokes e anti-stokes) assinalados, deveríamos esperar com a frequência de irradia ção a maior efeito Raman ressonante para as linhas Stokes do que para as anti-stokes, pela maior proximidade das pri meiras com o pico de absorção, enquanto que para a frequēn cia de irradiação c as linhas anti-stokes è que deveriam $\underline{a}$ presentar maior efeito Raman ressonante. Isto vale, eviden temente, se supusermos a dependēncia com a frequēncia de espalhamento Raman.

A medida da relação de intensidade anti-stokes pa ra stokes, em vārias frequēncias de excitação, seria um teste sobre a validade desta dependēncia.

Neste capitulo investigaremos o comportamento da relação de intensidade anti-stokes/Stokes para a frequēn 


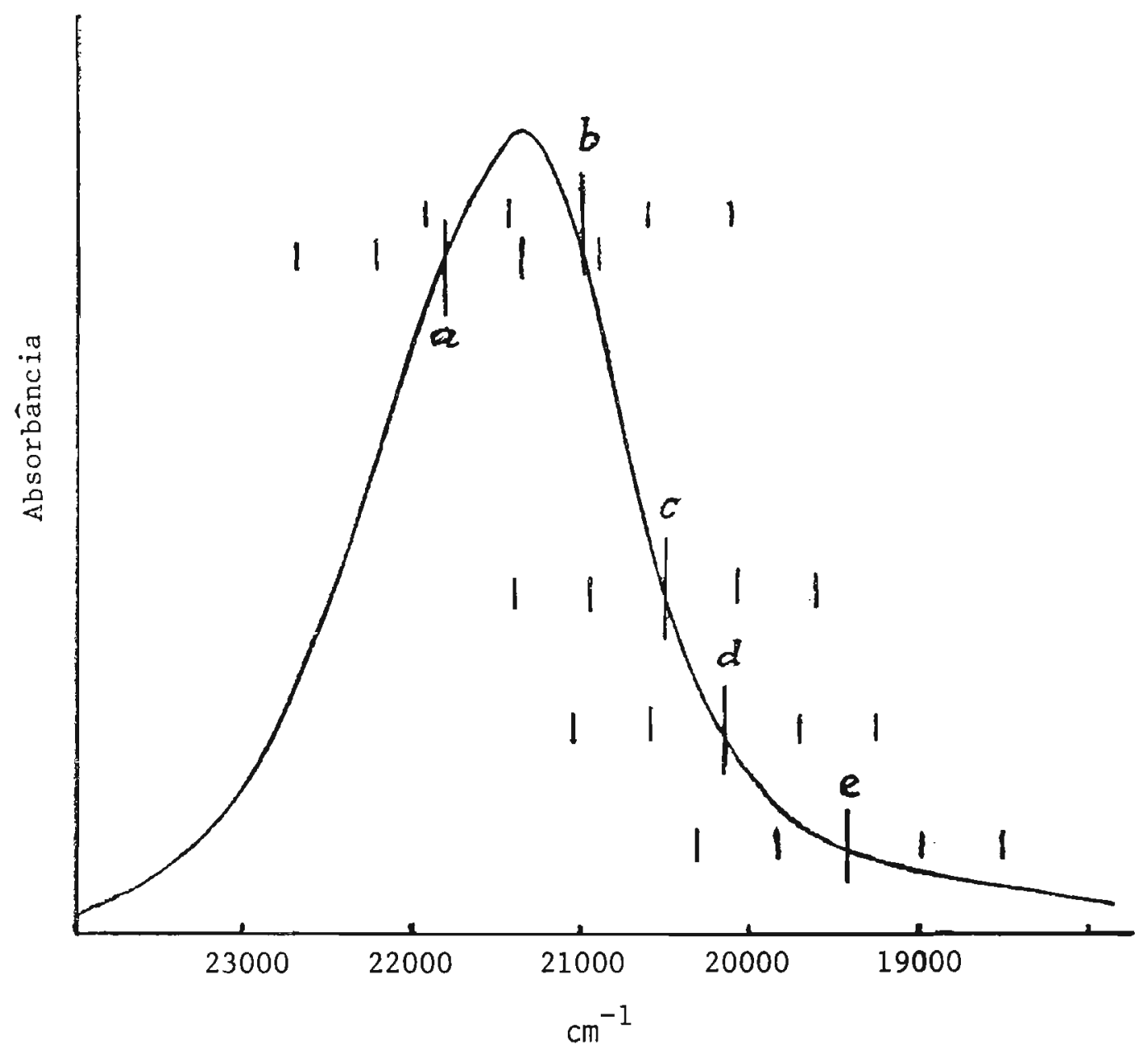

Figura 5.1. Posição relativa, na banda de absorção no visível, das 1 inhas de excitação $(a: 457,9, b: 476,5$, $c: 488,0, d: 496,5, e: 514,5 \mathrm{~nm})$ e das 1 inhas Raman v e $2 v_{1}$, Stokes ( $\bar{a}$ direjta) e anti-stokes (à esquerda). 
cia totalmente simétrica $v_{1}=454 \mathrm{~cm}^{-1}$, do $\left(M_{0} S_{4}\right)^{2-}$ e de sua primeira harmônica. Estes resultados serão tratados segundo as expressões teōricas de Nafie, Stein e Peticolas ${ }^{2}$ e serā obtido o valor da frequência efetiva $\left(\nu_{e}\right)$ para o estadoexci tado e o termo de amortecimento $(\Gamma)$ para o estado excitado. Estes parametros serão tambēm obtidos atravēs do perfīl de excitação.

O objetivo principal serā, contudo, mostrar a depen dēncia da intensidade no efeito Raman ressonante não somen te com a frequência de excitação (como é considerado na qua se totalidade dos trabalhos publicados), mas tambēm com a frequência Raman espalhada, Stokes ou anti-Stokes.

\subsection{Parte Experimental}

0 composto $\left(\mathrm{NH}_{4}\right)_{2} \mathrm{MoS}_{4}$ foi preparado segundo Brauer ${ }^{3}$, borbulhando $\mathrm{H}_{2} \mathrm{~S}$ numa solução amoniacal de molibdato de amō nio. Do composto recristalizado utilizou-se solução $\left(10^{-3} \mathrm{M}\right)$ aquosa alcalina, para obtenção dos espectros. A estabilida de da solução foi verificada através do espectro de absor ção no visivel.

A excitação dos espectros Raman foi obtida com as radiações $514,5,496,5,488,0,476,5$ e $457,9 \mathrm{~nm}$ do lase.r de $\mathrm{Ar}^{+}$, empregando-se potência entre 20 e $100 \mathrm{~mW}$.Para não haver efeitos térmicos utilizou-se cela rotatōria para 1 iquido ${ }^{4}$, com cerca de $2500 \mathrm{rpm}$, mantendo-se o feixe do laser rasante 
à face interna da cela, para evitar correções por absorção. Como a largura de uma banda permanece constante para qualquer frequēncia de excitação as intensidades foram med $\underline{i}$ das pela altura do pico. Foram efetuadas correções devidas ã sensibilidade espectral do instrumento e variaçãoda fenda es pectral, que foi mantida ao redor de $7 \mathrm{~cm}^{-1}$.

Para obtenção dos perfís de excitação utilizou-se co mo padrão interno $\mathrm{KNO}_{3}$, em concentração $0,5 \mathrm{M}$, e através de sua razão de intensidade anti-stokes/Stokes determinou-se a temperatura de $300 \mathrm{~K}$ para a amostra.

5.3. Resultados e Discussão

Na figura 5.2 são mostrados os espectros Raman da banda $454 \mathrm{~cm}^{-1}\left(v_{1}\right)$ e sua primeira harmōnica, stokes e antiStokes, para irradiação com 457,9 e 488,0 nm (a e c da Figu ra 5.1). Na Tabela 5 .I estão os valores experimentais de intensidade, medida direta e com as correções jāmencionadas (sensibilidade espectral do instrumento e largura espectral da fenda), além da correção para a quarta potência da frequên cia espalhada e fator de Boltzmann para as linhas anti-Stokes. A expressão teōrica para a relação de intensidade anti-Stokes/Stokes, dada por Nafie e col. ${ }^{2}$, pode ser escrita, considerando-se os valores experimentais de intensidade $\left(i_{n}\right)$ :

$$
r_{n}=\frac{i_{n}^{A}}{i_{n}^{S}}\left(\frac{v-n \nu_{R}}{\nu+n \nu_{R}}\right)^{4} B_{n}^{-1} \propto \frac{Q_{1}^{A} Q_{2}^{A} \ldots Q_{m}^{A} \cdots Q_{n}^{A}}{Q_{1}^{S} Q_{2}^{S} \ldots Q_{m}^{S} \ldots Q_{n}^{S}} .
$$




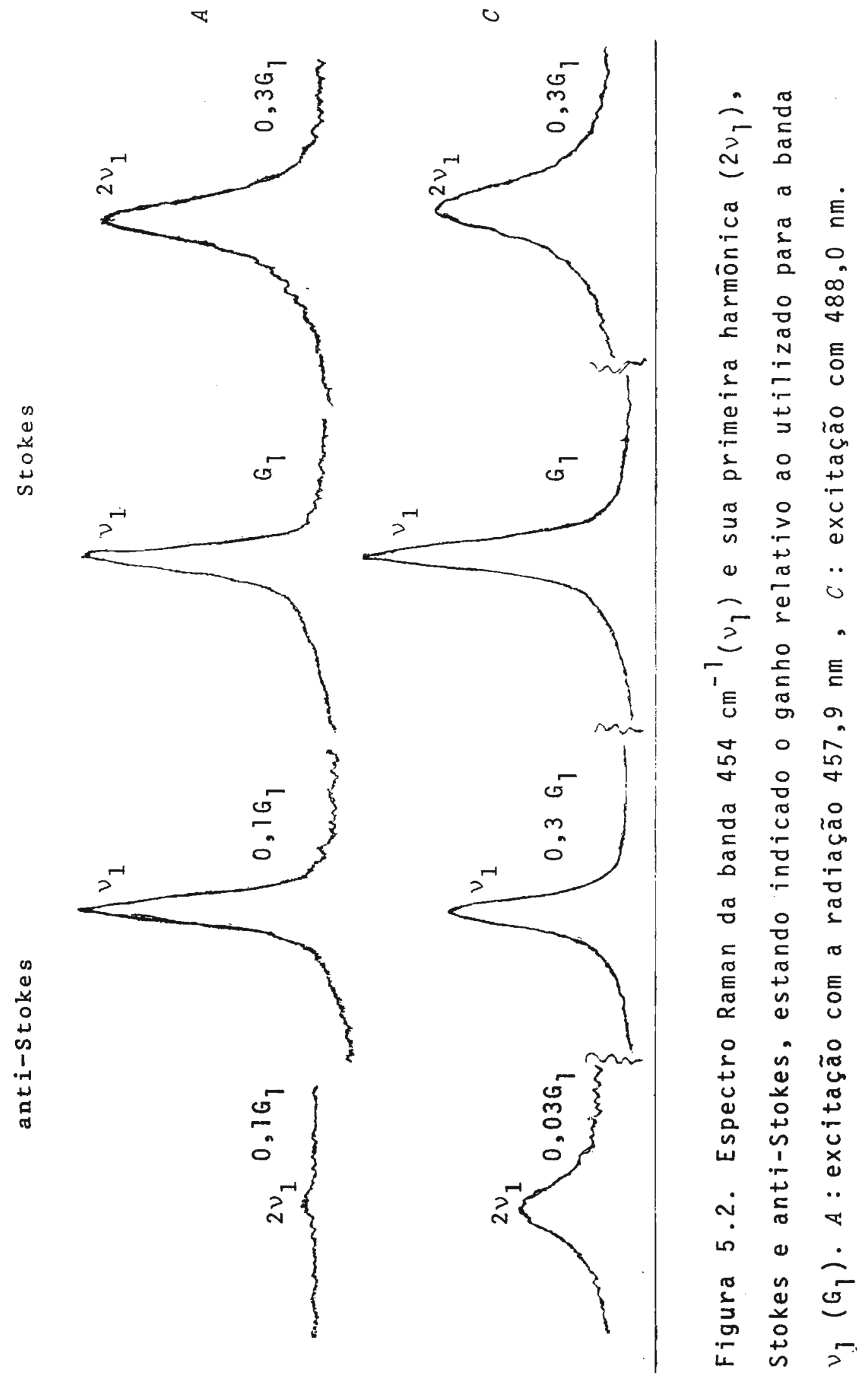


TABELA 5. I.

Valores de intensidade para $0 \operatorname{Mos}_{4}{ }^{2-}$

Valores experimentais sem correções:

\begin{tabular}{|c|c|c|c|c|c|c|}
\hline \multirow{2}{*}{$\begin{array}{l}\text { exc. } \\
(\mathrm{nm})\end{array}$} & \multicolumn{3}{|c|}{ anti-stokes } & \multicolumn{3}{|c|}{ Stokes } \\
\hline & padrão & $2 v_{1}$ & $v_{1}$ & $v_{1}$ & $2 v_{1}$ & padrão \\
\hline 514,5 & 3,5 & 7,0 & 79 & 106 & 6,5 & 250 \\
\hline 496,5 & 1,2 & 7,7 & 145 & 346 & 45,5 & 77 \\
\hline 488,0 & 1,8 & 14,5 & 315 & 1500 & 288,0 & 177 \\
\hline 476,5 & 0,4 & 2,5 & 67 & 460 & 115,0 & 33 \\
\hline \multirow[t]{2}{*}{457,9} & 0,3 & 0,4 & 15 & 150 & 42,0 & 13 \\
\hline & Valores & acima & $\operatorname{com}$ & \multicolumn{2}{|c|}{ s correções } & indicadas: \\
\hline 514,5 & 362 & 375 & 563 & 133 & 8,3 & 330 \\
\hline 496,5 & 106 & 363 & 900 & 323 & 50,5 & 93 \\
\hline 488,0 & 149 & 640 & 1827 & 1314 & 290,0 & 188 \\
\hline 476,5 & 30 & 98 & 353 & 361 & 104,5 & 31 \\
\hline 457,9 & 19 & 14 & 67 & 100 & 32,0 & 11 \\
\hline
\end{tabular}


onde $\nu$ è a frequência de excitação $\left(\mathrm{cm}^{-1}\right), \nu_{R} \bar{e}$ a frequência vibracional Raman $\left(\mathrm{cm}^{-1}\right), n \bar{e}$ o nümero quāntico vibracional, $B=\exp \left(-h c n \nu_{R} / k T\right)$ è o fator de Boltzmann e $Q_{m}=1 /\left\{\left(\nu_{e}-\nu \pm m \nu_{R}\right)+\Gamma^{2}\right\}$, com o sinal superior vālido para as linhas stokes (S) e o si nal inferior para as linhas anti-stokes (A). $r_{n} \bar{e}$ obtido da razão entre os valores já corrigidos da Tabela 5.I.

Num gräfico de $r_{n}$ versus $v$ as curvas cortam a linha $r_{n}=1,0$ para $\nu=\nu_{e}$, pois neste caso $Q_{m}^{A} / Q_{m}^{S}=1$. Na Figura 5.3 estão representados os valores experimentais de $r_{n}$ em função da frequência de excitação e a curva por estes pontos corta a linha $r_{n}=1,0$ em aproximadamente $21000 \mathrm{~cm}^{-1}$, que seria 0 va lor de $v_{e}$. Obtido o valor de ve pode-se determinar $r$ pelo mé todo dos minimos quadrados aplicado aos valores relativos $\left(r_{n}-\left(Q_{1}^{A} \ldots Q_{n}^{A}\right)\left(Q_{1}^{S} \ldots Q_{n}^{S}\right)^{-1}\right) / r_{n}$. Obteve-se desta forma $\Gamma$ apro ximadamente $1100 \mathrm{~cm}^{-1}$. O emprego dos valores relativos evita maior peso para os pontos com maior divergência entre o teó rico e o experimental.

Na Tabela 5.II estão os valores experimentais e teō ricos, de $r_{n}$, para as vārias frequências de excitação.

Das expressões teóricas para a intensidade de uma $1 \underline{1}$ nha Raman, dada por Nafie e col. ${ }^{2}$, podemos escrever a rela ção com os valores experimentais $\left(i_{n}\right)$ :

$$
i_{n} B_{n}^{-1}\left(\nu \bar{f} n \nu_{R}\right)^{-4} \propto \prod_{m=0}^{n}\left\{\left(\nu_{e}-\nu \pm m \nu_{R}\right)^{2}+\Gamma^{2}\right\}^{-1}=Q_{0} Q_{1} Q_{2} \ldots Q_{n} .
$$


74

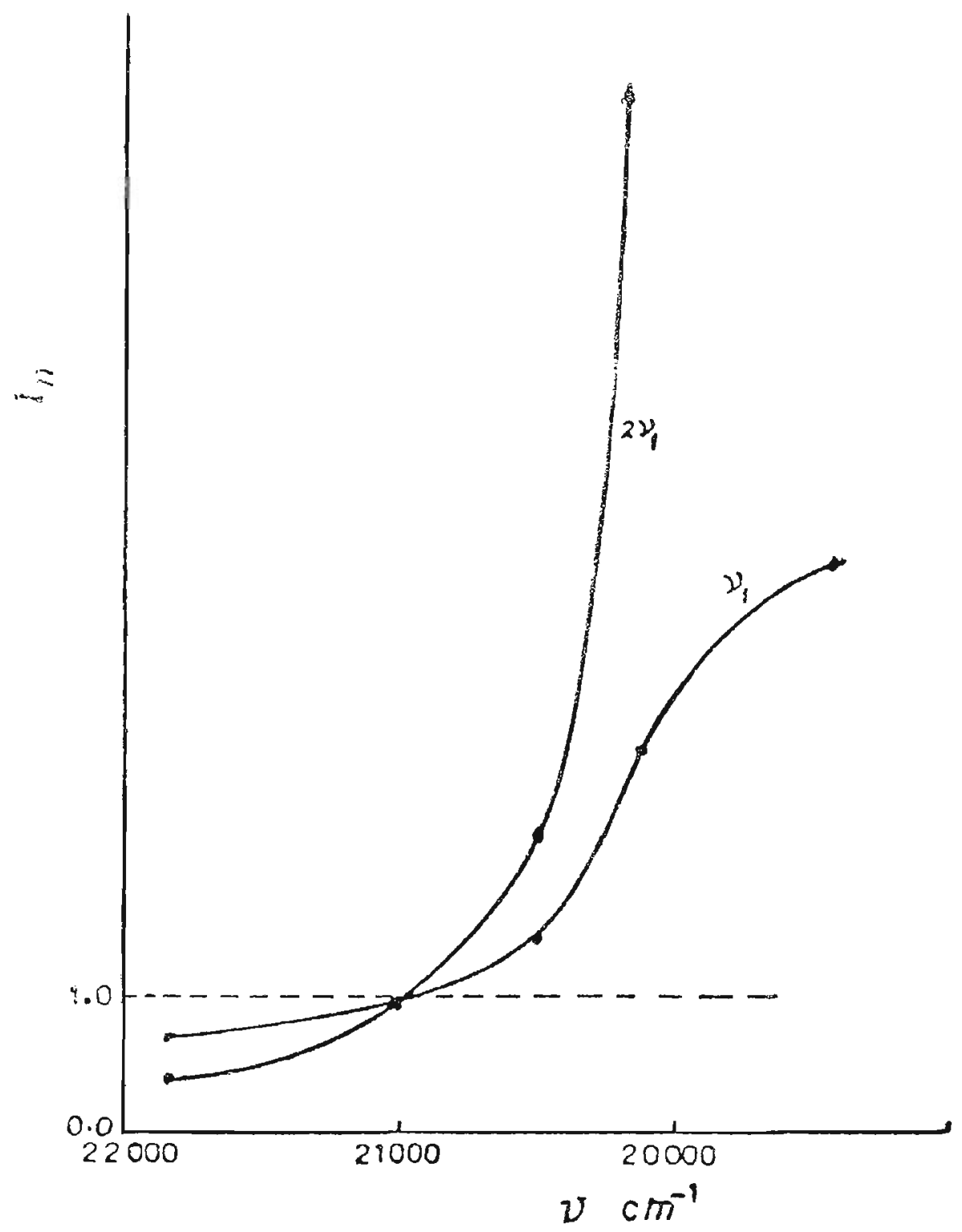

Figura 5.3. Valores experimentais de $r_{n}$ (V. expressão (I)) em função da frequēncia de ex citação. As curvas cruzam a linha $r_{n}=1,0 \mathrm{em}$ $v=v_{e}=21000 \mathrm{~cm}^{-1}$. 
TABELA 5. II .

Valores da razão de intensidade anti-Stokes/Stokes para $v_{1}\left(454 \mathrm{~cm}^{-1}\right)$ e sua harmōnica, segundo a expressão (I).

\begin{tabular}{|c|c|c|c|c|}
\hline \multirow{2}{*}{$\begin{array}{c}\text { Excitação } \\
(n m)\end{array}$} & \multicolumn{2}{|c|}{ Fundamental } & \multicolumn{2}{|c|}{ Harmōnica } \\
\hline & Obs. & Calc. & Obs. & $\mathrm{Calc}$. \\
\hline 514,5 & 4,2 & 2,2 & 45,4 & 9,7 \\
\hline 496,5 & 2,8 & 2,1 & 7,2 & 7,6 \\
\hline 488,0 & 1,4 & 1,8 & 2,2 & 4,1 \\
\hline 476,5 & 1,0 & 1,0 & 0,9 & 0,9 \\
\hline 457,9 & 0,7 & 0,5 & 0,4 & 0,1 \\
\hline
\end{tabular}

Da expressão (II) podemos calcular o perfíl teōrico, dado pelo produto $Q_{0} Q_{1}$ para a fundamental e por $Q_{0} Q_{1} Q_{2}$ para a primeira harmōnica, em função da frequência de excitação. Ajustando os parametros $v_{e} e r$ para este perfil coincidir com o experimental obteve-se valores concordantes com os ob tidos pela relação de intensidade anti-stokes/Stokes, poden do-se considerar para estes parametros os valores:

$\nu_{e}=21000 \pm 100 \mathrm{~cm}^{-1}$ e $\Gamma=1100 \pm 100 \mathrm{~cm}^{-1}$.

Na Figura 5.4 estão os perfís teóricos para a fre quência fundamental e harmōnica, Stokes e anti-stokes, sendo indicados os pontos experimentais. Estes perfís foram traça dos normalizando-se a intensidade nos picos em 100. Na Tabe 

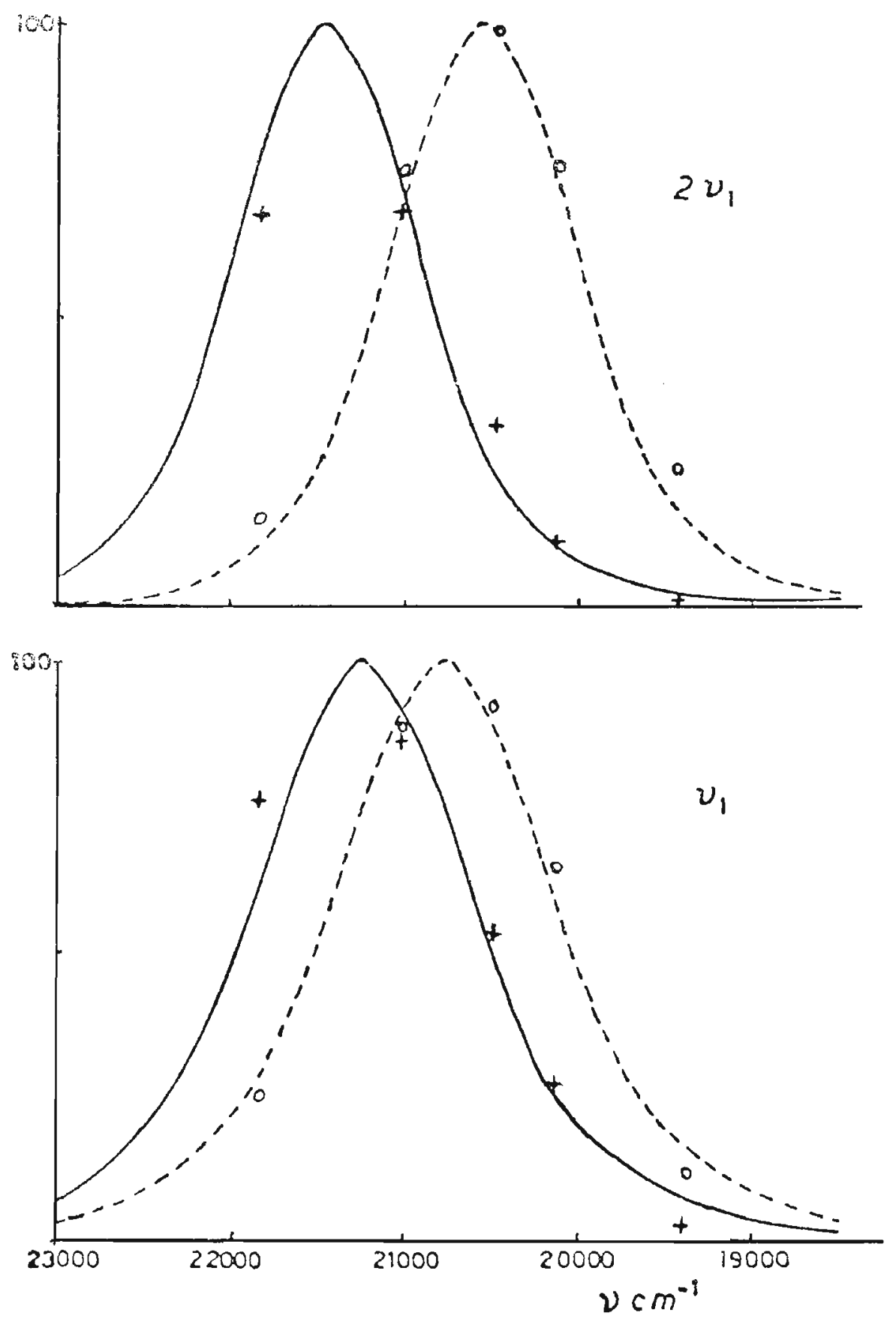

Figura 5.4. Perfîl de excitação (normalizado) para as frequēncias $v_{1}$ e $2 v_{1}$, stokes(teōr. exp.+) e anti-stokes (teōr.- - ;exp.o). Valores teōricos obtidos da equação (II). 
1a5.III estão os valores teōricos e experimentais (normali zados) para as frequēncias de excitação utilizadas.

TABELA 5. II .

Intensidade das bandas $v_{1}\left(454 \mathrm{~cm}^{-1}\right)$ e harmōnica do $\operatorname{Mos}_{4}{ }^{2-}$, Stokes e anti-Stokes.valores calculados da expressão (II).

\begin{tabular}{|c|c|c|c|c|c|c|c|c|}
\hline \multirow{3}{*}{$\begin{array}{c}\text { Excitação } \\
\left(\mathrm{cm}^{-1}\right)\end{array}$} & \multicolumn{4}{|c|}{ Fundamental } & \multicolumn{4}{|c|}{ Harmōnica } \\
\hline & \multicolumn{2}{|c|}{ Stokes } & \multicolumn{2}{|c|}{ anti-Stokes } & \multicolumn{2}{|c|}{ Stokes } & \multicolumn{2}{|c|}{ anti-Stokes } \\
\hline & obs. & calc. & obs. & $\mathrm{calc}$. & obs. & calc. & obs. & calc. \\
\hline 19436 & 3,0 & 8,2 & 11,7 & 17,8 & 0,5 & 1,7 & 23,0 & 16,6 \\
\hline 20140 & 26,2 & 27,8 & 63,9 & 59,4 & 10,8 & 9,8 & 76,0 & 74,7 \\
\hline 20492 & 52,5 & 50,8 & 92,2 & 89,4 & 30,4 & 24,1 & 98,0 & 99,5 \\
\hline 20982 & 86,5 & 91,8 & 88,1 & 94,0 & 66,8 & 67,7 & 73,5 & 71,5 \\
\hline 21839 & 76,8 & 61,3 & 25,4 & 28,9 & 65,6 & 76,8 & 16,1 & 10,3 \\
\hline
\end{tabular}

Observa-se na Figura 5.4 que para as linhas Stokes hã um deslocamento dos picos para o lado de frequências mais altas, em relação a $\nu_{e}$, enquanto que para as anti-stokes es te deslocamento é para o lado de frequēncias mais baixas. Este deslocamento aumenta com o número quāntico vibracional. Este resultado esta em concordância com o deslocamento dos picos observados no perfỉl de excitação do $\mathrm{Cu}_{3} \mathrm{PS}_{4}$.

Entre o pico do espectro de absorção no visível, em 
aproximadamente $21400 \mathrm{~cm}^{-1}$, e o valor de $v_{e}$ encontrado obser va-se uma diferença da ordem de $400 \mathrm{~cm}^{-1}$, sugerindo que o $p \underline{i}$ co de absorção corresponde a transição $0 \rightarrow 1$, enquanto que $\nu_{e}$ corresponde a transição $0 \rightarrow 0$.

\section{REFERENCIAS}

1 Ranade,A., Stockburger,M.: Chem. Phys. Letters $22,257(1973)$.

2 Nafie,L.A., Stein,P. e Peticolas,W.L.: Chem.Phys. Letters $12,131(1971)$.

3 Brauer,G.(ed.): Handbook of Preparative Inorganic Chemistry, vo1.2, 2a.ed. Academic Press, N.Y. (1965).

4 Kiefer,W. e Bernstein,H.J.: Appl.Spectry. 25, 500 (1971). 